\title{
QUÉ SIGNIFICAN ASPECTUALMENTE ALGUNOS VERBOS Y QUÉ PUEDEN LLEGAR A SIGNIFICAR*
}

\author{
ELENA DE Miguel \\ Universidad Autónoma de Madrid \\ elcna.demiguel@uam.es
}

\begin{abstract}
Resumen
The present paper investigates the possibility of establishing aspectual verb classes from the perspective of an extended notion of lexical aspect. The hypothesis it is based on (within the theoretical framework of Pustejovsky, 1991, 1995, 2000) assumes that the information codificd in the Qualia Structure of the predicate argumonts interacts within the lexicon with the Event Structure of the verb in order to generate certain aspectual specifications which, in turn, determine the syntactic bchaviour of the verb. According to this approach, the compositional nature attributed traditionally to the lexical aspect becomes a property of the level of the lexicon, which allows to overcome the difficultics arising from the aspectual alternations of the verbs, pointed out by traditional syntactic as well as semantic analysis.
\end{abstract}

\section{LAS CLASIFICACIONES DE VERBOS. INTRODUCCIÓN}

Preocupación básica del estudio gramatical a lo Iargo de la historia ha sido la de intentar establecer las clases de palabras o categorías gramaticales existentes. Muchos han sido los esfuerzos para delimitar los distintos grupos en que se pueden clasificar las palabras de las lenguas y, aún más, para discriminar los criterios homogéneos y unívocos que permitan llevar a cabo una clasificación rigurosa y coherente ${ }^{1}$. Así lo manifestaba Salvador Fernández. Ramírez, al recoger las palabras de Erasmo de Rotterdam en su Elogio de la Locura:

\footnotetext{
* La investigación que subyace al presente artículo ha sido presentada en versiones previas en el II Curso Europeo sobre El verbo y sus clasificaciones: aplicaciones lexicográficas, iraductológicas, computacionales y metateóricas, en la Universidad de Alicante (marzo, 2003), en el Ciclo Linguístico de Braga, en el Centro de Estudios Humanisticos de la Universidade do Minho, Braga (abril, 2003) y en cl XXXIII Simposio de la Sociedud Española de Lingüistica, en la Universitat de Girona (diciembre, 2003). Agradezco a las audiencias de los distintos foros las observaciones y comentarios sobre esas versiones previas, y sobre todo a sus organizadores las invitaciones a presentar la investigación en curso. En especial, quiero expresar mi agradecimiento a José Luis Cifuentes y Carmen Marimón, editores de este volumen. También quiero dar mis más cariñosas gracias a Volha Batsiukova y a Ana Serradilla, por sus sugerencias y comentarios sobre esta versión del trabajo. La investigación ha sido financiada por el Proyecto de Investigación FG 05 (Las expresiones idiomáticas con verbos de movimiento) del Programa de Apoyo a Grupos Emergentes de la Universidad Autónoma de Madrid.

1 En efecto, el establecimiento de las clases de palabras (en algún momento también llamadas con el término menos adecuado de partes de la onación) es un tema recurrente en la tradición gramatical, desde los griegos a las gramáticas de los siglos XVIII y XIX, estudiadas por Gómer. Asencio (1981).
} 
Sé de cierto hombre, ya entrado en los sesenta, una cminencia en griego, latín, matemáticas, filósofo, médico, sin rival en todas estas cosas, que, al margen de todo, hace ya más de veinte años estruja su mollcra y se atomenta con el estudio de la gramática. Pues bien, según me dice, scría feliz si pudiera vivir hasta establecer con certeza la distinción entre las ocho partes de la oración, algo que ni escritores griegos ni latinos lograron hacer de forma definitiva (Erasmo, 1511 [1984]: 97-98)

Las distintas cscuelas y modelos gramaticales y lingüísticos se han servido, en sintonía con los postulados básicos de sus teorías o de sus modus operandi, de diferentes tipos de criterios a la hora de establecer las clases de palabras: semánticos, morfológicos, funcionales, distribucionales. Aunque no es un tema definitivamente resuelto ${ }^{2}$, el momento actual de la investigación parecc haber optado de manera bastante general por la utilización de un criterio formal a la hora de definir a qué categoría gramatical pertenece una determinada palabra: de ahí que en los manuales escolares aparezea ya incluido dentro de la clase determinante cierto grupo de palabras, tradicionalmente llamadas adjetivos determinativos, que comparten las propiedades formales de los artículos y no las de sus homónimos clásicos, los adjetivos (argumentales, relacionales o calificativos). También en el caso de la categoría verbo el criterio para adjudicar una determinada palabra a esa clase parece que ha de ser formal. Pero también el intento de clasificar formalmente los verbos plantea problemas dc forma reincidente.

\subsection{En qué consiste ser verbo y qué clases de verbos se han propuesto}

Desde una perspectiva formal, en el sentido de configuracional, podría decirse que el verbo es la palabra que constituye el núcleo de un sintagma (al que se llama Sintagma Verbal, SV, precisamente por ser el verbo su núcleo) y que esa condición de núcleo le capacita para regir los complementos que potencialmente formen parte del sintagma ${ }^{3}$. Tradicionalmente se ha supuesto que los complementos regidos se encuentran de alguna manera scleccionados por el núcleo que los rige. Esto es, el verbo sería en principio una palabra dotada de la posibilidad de seleccionar semántica y formalmente uno o dos complementos (sintagmas que complementen o completen su significado) ${ }^{4}$. Ahora bicn, como resulta evidente, no todas las palabras que llamamos verbos seleccionan sus complementos: no to hacen los verbos copulativos (ser, estar; parecer) ni los pseudocopulativos (ponerse, volverse, seguir); tampoco

2 Sobre el tipo de cuestiones que obstaculizan el que se llcguc a un acuerdo definitivo tanto acerca del catálogo de las clases posibles de palabras como acerca de los criterios idóneos para determinarlas, el lector puede consultar Bosque (1989).

3 Por supuesto, al hablar de la definición formal de un verbo se puede estar aludiendo también a sus propiedades morfológicas, que lo distinguen de forma nitida de las atras siete clases de palabras; así de acuerdo con Crystal (1991), sub voce verb, 4The FORMAL definition of a verb refers to an clement which can display MORPHOLOGICAL contrasts of TENSE, ASPECT, VOICE, MOOD, PERSON and NUMBER» [mayúsculas en el original]. De acuerdo con Alcoba (1999: 4917), «el verbo es la palabra flexiva por excelencia, por el número de significados, de tiempo, aspecto y modo, y de número y persona; y por las variaciones que de tales significados pueden expresar las distintas formas de un verbo» a pesar de lo cual, a la hora de definirlo, cl autor opta por otro tipo de criterio: «cl verbo es una cłase de palabras que significan un evento, una acción, proceso o estado. Son núcleos predicativos y núcleos de complementación sintáctica» (Alcobá, 1999: 4917).

4 Sobre la noción de régimen, cl lector encontrará algunas consideraciones en Campos (1999) y Cano Aguilar (1999). 
seleccionan su complemento los verbos de soporte (hacer un ruido; hacer una visita) y los que Bosque (2001a) denomina ligeros pero de más peso (heavier light verbs), que podríamos traducir como 'verbos cuasi-de soporte' (cometer un delito, emprender una campaña); ni los verbos que experimentan extensiones de tipo metafórico que les permiten entrar en expresiones idiomáticas cuyo contenido no se deduce del de la suma de sus constituyentes (salir en la foto; meter la pata; dar rodeos) . $^{5}$.

Tampoco toda palabra clasificada como verbo, sola o en conjunción con sus complementos, selecciona semánticamente su sujeto. La selección semántica del sujeto de los verbos arriba mencionados es llevada a cabo en exclusiva o fundamentalmente por el sintagma que ocupa la posición de complemento del verbo (como prueban ejemplos sencillos del tipo \{Juan/*el coche\} hizo una visita; $\{$ "Juan/el coche\} hizo un extraño).

En suma, existen verbos que no seleccionan sus argumentos (complemento(s) y/o sujeto), a pesar de lo cual no se pone en duda su condición verbal. De hecho, no parece que ésta sea requisito para la selección semántica de argumentos. Es bien sabido que existen otros elementos capacitados para seleccionar semánticamente los argumentos de que se predican: es el caso, por ejemplo, de los llamados predicados secundarios, que categorialmente suelen corresponder a sintagmas adjetivos y preposicionales (es decir, a elementos no verbales), y que llevan a cabo la selección semántica de su sujeto: el atleta llegó hasta la playa la semana pasada \{cansado/de los nervios\}/la carretera llegó hasta la playa la semana pasada *\{cansada/de los nervios\}; asimismo, existen adjetivos, llamados argumentales, que materializan los argumentos de los nombres que los seleccionan (por ejemplo, la conquista norteamericana y soviética del espacio en la segunda mitad del siglo pasado; la conquista espacial, etc.). En definitiva, el criterio utilizado para definir un verbo no podrá ser el de la selccción semántica, puesto que a través de este lo que identificamos son «predicados» y hay otras palabras y sintagmas que pueden funcionar como tales.

Con independencia de qué criterio sea el usado para definir un verbo (y, en consecuencia, cómo hemos llegado a decidir que unas palabras pertenecen a esa clase y otras no), lo que resulta evidente es que, desde el punto de vista de los requisitos semánticos, y también descle la perspectiva de las exigencias sintácticas, hay muchos lipos de verbos distintos; es decir, hay muchas palabras que consideramos verbos cuyo comportamiento como predicados seleccionadores de argumentos y como núcleos rectores de complementos son muy distintos. Así, existen verbos que no admiten complementos (llegar) y verbos que los exigen (llevar), verbos que los necesitan pero pueden esporádicamente perderlos (comer un bocadillo/comer) y verbos que no los llevan pero en algún caso los admiten (vivir/vivir una aventura), verbos con un complemento y verbos con dos (comer un bocadillo/decir algo a alguien), y verbos que tienen la posibilidad de manifestar sus complementos con diferentes realizacio-

5 Los límites entre las expresiones que contienen verbos de soporte (dar un beso, iniciar un asalio), las expresiones que tradicionalmente se conocen con el nombre de 'colocaciones' (prestar alención, emprender una campaña) y las expresiones idiomáticas o metafóricas (tomar el pelo, caer gordo, salir el sol) son cn ocasiones demasiado tenues y difusos y parecen apuntar a la existencia de un contimum en el que el verbo va perdiendo gradualmente significado ( $y$, en consecuencid, capacidad para selcccionar argumentos). Los tres casos mencionados se localizarían en la parte baja de esa escala o continum. Cft. à este respecto Bosque $(1997,2001 \mathrm{a}, 2001 \mathrm{~b})$, Bjerre (1999) y Grupo II.EA (2004). La hipótesis de que los verbos entran con más facilidad en expresioncs idiomáticas y en cxtcnsiones méafóricas cuanto más abajo se encuentran en la escala de la significación será explotada en este trabajo más adelante (cfi. $\S 2.3$ ). 
nes sintácticas (esperar que algo ocurralesperar a que algo ocurra; dudar algo/dudar de algo; cargar botellas en el camión/cargar el camión con botellas); hasta el punto de que encontramos verbos que pueden construirse sin complemento (pensar) o con él y, cn este caso, manifestarlo de varias formas (pensar \{algo/en algo\}).

Los verbos arriba mencionados (llegar, llevar, comer, esperar, dudar, cargar, pensar) son, en efecto, verbos todos ellos, aunque no compartan sus requisitos de selección y régimen. Lo que sí comparten es el hecho de estar dotados de significado, y de ello derivan los requisitos de selección y subcategorización de sus argumentos. Son, pues, 'verbos predicativos". Pero también existen verbos sin significado, o con poca carga semántica, que no predican; como ya se mencionó, los copulativos (ser, estar, parecer), los pseudocopulativos (volverse, ponerse, seguir, ...) y los verbos de soporte o ligeros (hacer en hacer visitas, dar en dar besas) coinciden en no seleccionar sus argumentos: no son, pues, predicados.

En suma, la consideración de en qué consiste ser verbo dista mucho de tener una respuesta inmediata $y$, en consecuencia, el establecimiento de las clases posibles de verbos se vuelve también una cuestión relativamente escurridiza. Al tiempo, para el estudioso del lenguaje ha resultado siempre muy atractivo el hecho innegable de que, dentro de la heterogeneidad, se pueden establecer agrupaciones de piezas verbales que manifiestan un comportamiento sintáctico similar: por eso ha sido constante a lo largo de la historia el intento de establecer clases de verbos coherentes y productivas. Las propuestas de clasificación han sido muchas y han seguido pautas diferentes, aunque tal vez más estrechamente relacionadas de lo que en algunos momentos haya podido parecer. De las primitivas clasificaciones (por poner un par de ejemplos notables, la de Aristóteles y al de Apolonio Díscolo) a las actuales no tanto ha cambiado. Parecería que seguimos dando vueltas a los mismos problemas, como recogía la cita de Erasmo.

\subsection{Algunas propuestas concretas de clasificación verbal. Criterios en que se basan y dificultades que plantean}

A la hora de clasificar los verbos se puede, en efceto, acudir a nociones de tipo semántico o a criterios de tipo estructural o configuracional.

Según el primer tipo de parámetro, podemos agrupar los verbos, de acuerdo con ciertos rasgos de su significado, dentro de macroclases del tipo verbos de lengua, entendimiento y sentido, verbos de valoración o evaluación, verbos de creación y consunción, de stirgimiento o acabamiento, de percepción (visual e intelectual), de influencia, de movimiento, de cambio de estado (físico y psicológico) o de cambio de locación, de afección psicológica, de objeto afectado, efectuado, percibido o desplazado, etc..$^{\sigma}$ estas etiquetas, algunas más clásicas que otras, aluden a nociones o contenidos en ocasiones difíciles de delimitar y en

\footnotetext{
6 Las clasificaciones de verbos por su significado son muchas y muy variadas, tanto en los criterios como en la terminología utilizada para eslablecerlas: sirva como pequetia muestra de la amplia gama de variación existente el trabajo de Comcsaña (2002); la autora se ocupa de un grupo de verbos que denomina de opinion y conocimiento pero señala que están incluidos, en parte o en su totalidad, entre los que Cano Aguilar (1981) denominó verbos de percepción intelectual, Halliday (1985), cognition verbs y Lcvin (1993), verbos declarativos, por citar solo algunas propuestus dentro de macos metodológicos bien diferenciados. La autora, en realidad, menciona hastiz cuatro posibilidades más.
} 
ocasiones poco iluminadores a la hora de explicar los comportamientos sintácticos de los verbos recogidos bajo alguna de cllas?

Entre las clasificaciones de verbos más extendidas y aceptadas se encuentra la que distingue entre transitivos e intransitivos, cuya naturaleza es más sintáctica que semántica (aunque tampoco esta es un afirmación incontrovertida). Más reciente, pero también bastante generalizada en el momento actual, es la clasificación que distingue a su vez, dentro de los verbos intransitivos, los inacusativos y los incrgativos ${ }^{8}$. Muy explotadas en el momento actual son las clasificaciones que distinguen entre verbos que denotan eventos que inherentemente implican un final y verbos que denotan eventos que no implican un final ${ }^{9}$. Con ellas entramos en el terreno de las distinciones aspectuales, área que también ha motivado otras clasificaciones famosas: la de estados frente a eventos, la que distingue entre eventos durativos y puntuales, frecuentativos y semelfactivos, etc.; entre las clasificaciones de base aspectual con más éxito, sc encuentran la de Vendler (1967) —que distingue entre estados, logros, actividades y realizaciones-y la de Pustejovsky $(1991,1995)$-que subsume los logros y las realizaciones de Vendler y propone la existencia de tres tipos de eventos verbales: los estados, las transiciones y los procesos- ${ }^{10}$.

7 Así, entre las preguntas clásicas a las que debería dar respuesta nítida el lingüista se encuentra la de «cómo se define exactamente un objeto afectadon, noción algo imprecisa que, sin cmbargo, se ha usado a menudo para justificar el comportamiento de un determinado verbo frente a ciertos procesos sintácticos: por ejemplo, la formación de araciones modias, fenómeno del que se ha dicho que sólo experimentan los verbos de objeto afectado. Inmediatamente puede plantearse la objeción de en qué medida el objeto de cortar está afectado cuando es el pan y no cuando es la silla, dado que el primero acepta la construcción media y el segundo no (el pan congelado se corla fácilmente/ las sillas con carcoma se cortan fácilmente). Ln sentido estricto, la silla corlada cambia de estado (se vuclve «trozos de silla» pero ya no es «una silla») mientras que el pan congelado sigue siendo pan una vez cortado, así que desce una perspectiva semántica parece más afectudo silla (con carcoma) que pan. Desde una perspectiva sintáctica — tal y como definen Hale y Keyser (1993: 82) la noción de afcctación--, ambos sintagmas parecen ocupar la misma posición estructural y por tanto ser igualmente afectados. Por tanto, una etiqueta del tipo verho de objeto afectado rcsulta, en mi opinión, poco ủtil, en tanto no se establezca con precisión el criterio en qué se basa

8 Distinción originariamente propuesta por Perlmutter en el marco de la Gramática Relacional, que la gramática teórica, desde Burzio, en el modelo generativista de los años 80 , ha asumido, desarrollado y discutido, pero cuya verdadera naturalcza parcce aún por resolver; con independencia de la rentabilidad obtenida de la distinción (aplicada a la cxplicación de un notable conjunto de fenómenos morfológicos y sintácticos), la cuestión de si el parámetro que discrimina entre inacusatividad e inergatividad estriba en primcra instancia en las propiedades léxico-semánticas del verbo (de las que derivan a su vez las diferencias configuracionales) o si se trata de una diterencia configuracional en origen (con consecuencias en la interpretación) sigue siendo objeto de debate. Si se considera quc la base de la distinción es de tipo semántico, en la tradición gramalical española se puede rastrear un antecedente en Bello (1847), quien habló de verbos deponentes para aquellos que expresan un significado pasivo en su forma activa, en un sentido próximo a lo que se entiende por inacusativo. El lector puede consultar a este respecto De Miguel (1992), Cifuentes (1999), Mendikoetxea (1999), Castillo (2002), Alexiadou et alii (eds.) (2003) y Hemández Paricio (en prensa), entre otros.

9 Es la distinción establecida entre verbo perfectivo/no perfectivo, oposición que tambićn ha recibido otros nombres: télicalatélico; acabado/no acabado; delimitado/no delimitado; acotado/ no acotado, entre otros. Esta distinción se ve afectada, aparte de por la diversidad terminológica, por un problema clásico en la bibliografía sobre distinciones aspectuales: cl hccho de que la distinción se utiliza para discriminar verbos pero en realidad son los predicados (esto es, los verbos y sus complementos, y aun los adjuntos) los que se examinan para decidir cómo es el evento denotado. Para una y olra cuestión, véase De Miguel (1999).

10 Asimismo, una clasificación de los verbos en cspañol por su aspecto léxico es la de De Miguel (1999), deudora, en gran parte de la de Bertinetto (1981) para el italiano. Sobre la propuesta de Pustejovsky volveré más adelante en el texto $(\$ 2.1 .2)$. 
Por otro lado, teniendo en cuenta la función semántica de los participantes en el cvento, los verbos se han clasificado en verbos de estado, proceso y acción. Fsta distinción no es propiamente aspectual y se justifica por la existencia de comportamientos sintácticos difcrenciados, cuyas pruebas diagnósticas se han utilizado equivocadamente a veces como tests aspectuales ${ }^{11}$.

Las distintas clasificaciones mencionadas, y otras varias que se podrían citar, se entremezclan y cruzan a menudo, se prestan pruebas y datos, interactúan y se solapan; de ello acaba resultando un panorama que podría parecer desolador pero que es el que se corresponde con la realidad de los hechos lingüísticos. Veámoslo con un sencillo ejemplo: podría esperarse que ser verbo de afección psicológica tuviera cierta implicación aspectual, con ciertas consecuencias en la selección semántica de los argumentos y en la selección sintáctica de estos. Sin embargo, no todos los vcrbos incluidos en la clase de afección psicológica se comportan igual. Temer es estativo y por tanto no delimitado pero asustar es dinámico y delimitado. Así pues, dentro de una misma clase habrá que discriminar subclases de verbos de acuerdo con otros parámetros. Ahora bien, mientras que esto resulta relativamente fácil de llevar a cabo a propósito de temer y asustar, en la medida cn que los distintos autores están bastante de acuerdo en sus diferencias eventivas (cfr. Mosquera, 2001), no ocurre lo mismo respecto de otros verbos de afección psicológica; así, los autores discrepan acerca de los verbos del tipo de enamorarse, preocuparse: mientras que para algunos son estativos, otros aportan pruebas de su comportamiento como verbos dinámicos ${ }^{12}$.

Veamos algún otro caso problemático o, más bien, esquivo a las clasificaciones habituales en los términos en que se han formulado: si el ser verbo transitivo implica denotar un paso o transición, en principio, la caracterización de un verbo como transitivo parecería incapacitarlo para denotar un evento estativo (en los que no hay «paso» ni «transición»); sin embargo, hay muchos verbos transitivos que denotan eventos estativos: entre otros, amar y odiar. Es más, la expresión de un estado se puede materializar en un verbo transitivo (directo o indirecto: Juan detesta las acelgas; Juan cree en mi), en uno inacusativo (Falta café) y por supuesto en uno copulativo o en uno pseudocopulativo (.han está cansado; Juan sigue cansado).

De igual modo, el que un verbo sea caracterizado como inacusativo parece implicar en principio cierta especificación aspectual (télica), cierta selección semántica de su argumento (paciente) y cierta proyección sintáctica de este (interno al SV, a la derecha del verbo). Pero ninguna de las tres implicaciones se cumple, al menos, en español, de una manera clara.

\footnotetext{
11 Es el caso, por ejemplo, del test del imperativo, al que se ha recurrido a menudo para distinguir entre eventos estáticos (que no aceptan imperativo) y dinámicos (que hipotéticamente si lo aceplan), cuarto en realidad lo que diagnostica es la cxistencia de animacidad (y agentividad) en el sujeto (como prueba el hecho de que los verbos dinámicos de sujeto no agente no aceptan la construcción imperativa: "inace!). Véasc de nucvo De Migucl (1999: $\$ 46.3 .2 .1$.)

12 En Fernández Lagunilla y De Miguel (1999) los consideramos aventos complejos, compuestos de una fase de logro (aquella en que se produce el cambio a un estado nuevo) y una fase de estado (en la que se mantiene el muevo estado alcanzado). Así explicamos las autoras $\mathrm{cl} \mathrm{hecho} \mathrm{de} \mathrm{que} \mathrm{estos} \mathrm{verbos} \mathrm{respondan} \mathrm{a} \mathrm{ciertas} \mathrm{pruebas} \mathrm{como}$ dinámicos y puntuales (se preocupó \{sibitamentelese dia\}) y a otras como estáticos y durativos (atin se preocupal se preocupó durante años). Para la consideración de estos verbos como estativos, cfr. Marín (2004); para su consideración como logros compuestos de una făse de logro y otra de estado, véase en especial De Miguel y Fernández Lagunilla (2003)
} 
Así, si se considera que el ser inacusativo consiste en tener un sujeto paciente, entonces no todos los verbos de movimiento lo son, según ha probado Cifuentes (1999) para ejemplos como Juan llegó tarde a propósito para que todo el mundo se fijara en él. Este hecho no deja de ser curioso, en la medida en que precisamente el grupo de los verbos de movimiento ha sido ofrecido tradicionalmente como paradigma de la inacusatividad ${ }^{13}$. Asimismo, si todos los inacusativos fueran verbos télicos, no se explicaría por qué muchos de ellos no entran en construcción absoluta (*rodada la pelota, corrimos tras ella). Y, además, existe un notable grupo de verbos estativos (por tanto, atélicos) considerados inacusativos; faltar, quedar, sobrar, bastar, etc. En definitiva, no está claro qué es ser inacusativo y qué inergativo, ni a qué grupo pertenecen los verbos de movimiento; además, parece que los verbos de movimiento no se pueden atribuir en bloque al grupo de los inacusativos o al de los inergativos y, más aún, que hay casos en que un mismo verbo de movimiento manifiesta un comportamiento heterogéneo según el contexto (la primavera llegó muy prontólJuan llegó muy pronio para espiar; Juan corrió por el parquef.Juan corrió hasta la panadería).

Los hechos arriba reseñados obligan a asumir, entre otras cuestiones, que un mismo verbo puede pertenecer a diversas clases, que los verbos de una misma clase, evaluados desde otro tipo de parámctro, se agrupan en clases distintas, y que no siempre existe una relación directa y perfecta entre significado y configuración. Como adelanté, el panorama puede resultar desalentador pero los lingüistas no se desaniman y son muchos los intentos de proporcionar explicaciones válidas.

\subsection{Posibilidades de representar la relación léxico-sintaxis}

Desde el momento en que la información contenida en el léxico comienza a ser tenida en consideración para el estudio gramatical, los lingüistas se han planteado cn qué medida $y$ en qué sentido interactúan la información del léxico y la configuración sintáctica ${ }^{14}$. Un amplio conjunto de modelos teóricos, conocidos como derivacionales o proyeccionistas (entre los que se encuentran las distintas versiones del marco generativo, desde principios de los ochenta), asumen como supuesto básico de sus teorías que la semántica léxica de los predicados determina la estructuración de sus argumentos, y que de ella deriva su comportamiento sintáctico. Si se suscribe esta hipótesis, ha de asumirse también que los verbos cuentan con cntradas en el léxico en las que se especifica el número de argumentos de ese predicado (uno, dos, tres o ninguno), las posiciones sintácticas en que se proyectan (esto es,

13 Por supucsto, también es posible que el problema resida en que se hayan caracterizado como inacusativos verbos que no lo son, pero no hay en principio razones para excluir la posibilidad de que existan verbos inacusativos atélicos (cfr. De Miguel, 1992) y verbos inacusativos de sujcto agentc (cfr. Cifuentes, 1999). En ese caso, parece que ser inacusativo es ajustarse a cierta configuración (cf.. Pérez Jiménez y Moreno, en prensa). En los trabajos mencionados cn la nota 8 se pasa revista a estas cuestiones relacionadas con la naluraleza imprecisa de la inacusatividad.

14 La información contenida en el léxico es descartada para el estudio teórica por los distribucionalistas norteamericanos en la primera mitad de $\uparrow$ siglo pasado, por considerarla idiosincrásica e irregular y, en consecuencia, no abordable. Fl primer Chosmky, heredcro del distribucionalismo, la descarta también. Es recuperada, no obslante, para el csudio formal por el modelo generativo, entre otros, con el trabajo del propio Chomsky (1967). $\Lambda$ partir de ese momento el léxico va adquiriendo una relevancia creciente en las explicaciones sintácticas, hasta cl momento actual, en el que la disciplina ha experimentado, para muy diversas cscuclas y enfoques, un cambio de perspectiva de estudio que se conoce con el nombre de giro lexicista. 
las funciones gramaticales que desempeñan) y la función semántica de dichos argumentos, ya que cada uno de ellos representa a un participante en el evento denotado por el verbo. La codificación de estas informaciones es lo que se conoce con el nombre de estructura argumental. Los verbos que la comparten (esto es, que comparten los requisitos de selección de argumentos y régimen de los complementos) pertenecen a la misma clase, puesto que coinciden en una parte de su definición que condiciona el comportamiento sintáctico; esto es, coinciden en aquello que es visible para la clasificación. Por decirlo con palabras de Val Álvaro (1999):

[en la] definición del contenido de los vcrbos interviene un conjunto de componentes determinado $[\mathrm{y}$ ] lo intercsante desde la perspectiva sintáctica es que ese significado selecciona las posibles combinaciones de la unidad léxica predicaliva con otros constituyentes en la oración. En otros términos, que hay una relación directa entre el significado del verbo, construido a partir de elementos de un conjunto limitado, y las configuraciones sintácticas en que puede aparecer. (Val Álvaro, 1999: 130)

Desde esta perspectiva de análisis, diferentes comportamientos sintácticos implican diferentes estructuras léxicas; en el léxico se postularán diferentes entradas para la distintas configuraciones sintácticas. Así, la distinción entre verbos que pertenecen a la clase de los inergativos y los que pertenecen a la clase de los inacusativos, aunque se puede comprobar en la sintaxis, es de naturaleza léxica. Esto es, son las diferencias en la estructura léxica de unos y otros verbos las responsables de las diferencias sintácticas postuladas entre ambas clases (cfr. Herníndez Paricio, en prensa).

Por supuesto, son varias las cuestiones por resolver para explicar de forma adecuada cómo se predicen comportamientos sintácticos a partir de la información léxica: de acuerdo de nuevo con Val Álvaro (1999: 134), las preguntas básicas a las que debe intentar responder un enfoque derivacional son la de «qué tipo de información es relevante y cómo la representa el léxico» y la de "cómo se proyecta la información de las entradas léxicas en la estructura». Son posibles además otro tipo de preguntas: en primer lugar, cuál es el primitivo que determina la forma y composición de la estructura argumental: esto es, ¿̇son las funciones semánticas de los participantes (o argumentos) las que exigen una determinada materialización (como SSNN, como SSPP)? ¿o son las posiciones que ocupan los sintagmas en la estructura argumental las que determinan su función semántica? Si esta relación existe, sea cual sea el sentido en que se mantenga, hay que postular reglas de enlace entre posiciones sintácticas y funciones semánticas: ¿cuántas y cuáles son esas reglas? Y, más aún, ¿se puede postular un principio semántico básico que determine todas las propiedades de la estructura argumental de un predicado? Esto cs, ¿existe un primitivo responsable de la configuración sintáctica y de la interpretación semántica de los participantes en el evento? Si presuponemos que existe, ¿de qué naturaleza sería ese principio? Suponiendo que fuera el aspecto (como se ha considerado de una manera bastante general desde muy distintas perspectivas y articulaciones a lo largo de la última década del siglo pasado y cn lo que llcvamos del siglo XXI), ¿de qué manera opera? Esto es, ¿dónde se codifica su información y cómo? ¿En qué punto interfiere con las otras informaciones contenidas en la entrada léxica de un verbo? De nuevo, si el aspecto determina las funciones semánticas de los participantes y estos se ligan a posiciones predeterminadas en la configuración, ¿existe algún tipo de regla de enlace? ¿O, más bien, el aspecto determina la aparición de un argumento 
en una posición y de ella deriva su interpretación en términos de papeles semánticos? ¿A través de una regla de enlace? ? $^{5}$

Como vemos, son muchas las preguntas posibles y son también muchas las posibilidades de explicación. En el \$2.3. ofreceré una propuesta personal de explicación de cómo tiene lugar la interacción entre el aspecto del predicado y la información que aportan los argumentos a la interpretación del evento, pero de momento abandonamos la revisión del enfoque derivacional o proyeccionista.

Por supuesto, a la hora de explicar las relaciones entre el léxico y la sintaxis se puede adoptar una perspectiva de estudio distinta, que implica un sentido en la dirección de la relación opuesto al de los modelos proyeccionistas. Piénsese en el hecho bien conocido y argumentado de que la primitiva interpretación aspectual del evento denotado por un verbo puede cambiar dependiendo de la configuración sintáctica del predicado en que aparece: así, nadar es atélico pero nadar los cien metros es télico; escribir un poema télico y escribir atélico, por poner sólo un par de ejemplos. Es to que tradicionalmente se ha llamado la naturaleza composicional del aspecto léxico ${ }^{16}$. Piénsese asimismo en la existencia de verbos con distintas posibilidades de materialización de su estructura argumental: lo que se han llamado tradicionalmente las alternancias de diátesis, de las que son ejemplos clásicos cargar botellas en el camión/cargar el camión con botellas Para algunos autores, la causa de la diferente interpretación aspectual de unos y otros predicados no está relacionada en este caso con los papeles semánticos de los participantes (que son idénticos) ni con la información aspectual del verbo sino con la aportada por los constituyentes que forman parte del predicado, según se materialice este. Esta corrientc recibe el nombre de construccionista (y neo-construccionista en una versión más extrema) y reformula las relaciones aspectuales y las interpretaciones eventivas en términos de relaciones configuracionales que se mantiencn en la sintaxis ${ }^{17}$. Para el construccionismo, un verbo puede entrar en estructuras sintácticas distintas, ya que no conticne en su entrada léxica información específica sobre el comportamiento de sus argumentos ${ }^{18}$. Desde esa perspectiva, el conjunto de propiedades que llevan

15 El trabajo de Val Álvaro (1999) citado cn el texto constituye una interesante revisión de las cucstiones que se suscitan y del tipo de respuestas que se suelen dar. También lo es Hernández Paricio (en prensa). Más general y abarcador es el libro recién publicado de Moreno Cabrera (2003). Algunas de las preguntas esbozadas en el texto y sus posibles respuestas fueron ya recogidas en De Miguel (1992).

16 Véase a este respecto De Miguel (1999) y De Miguel y Fernández Lagunilia (en prensa).

17 El lector encontrará una interesante revisión de lass distintas perspectivas en Pérez Jinénez y Moreno (en prensa). Cfr, asimismo Demonte (2003)

18 Así, el hecho de que existan altcrnancias de diátesis, estructuras sintácticas que se rclacionan entre sí por medio de una oposición de tipo semántico, se considera prueba de que la difcrente configuración sintáctica es responsable de la interpretación eventiva. No obstantc, como a muchos otros argumentos, a este se le puede dar la vuelta: para los gramáticos proyeccionistas la existencia de alternancia de diátesis lo que prueba es que existen diferencias eventivas (aspectuales) básicas contenidas en el léxico y proyecładas cn la sintaxis. Esto es, mientras para los gramáticos construccionistas no existe un verho asociado a una estructura argunental, sino distintas configuraciones en la sintaxis de las que derivan las cstructuras argumentales, para los proyeccionistas habrá diferentes estructuras argumentales asociadas a las distintas interpretaciones aspectuales de un mismo verbo. En cualquier caso, el cstudio de las alternancias de diátesis en que participan los verbos parece clave para definir la relación entre sintaxis y semántica. (cfr. Vázquez et alii, 2000 y Fernández et alii, 2002). La línea de investigación desarrollada por García-Miguel, en el Proyccto ADESSE (Alternancias de Diálesis y Esquemas Sintáctico-Semánticos del Fspañol, presuponc que no existe correspondencia exacta entre construcción y significado sino que las distintas acepciones de los verbos están condicionadas en gran medida por el esquema sintáctico en que aparezca el verbo en cuestión ( clt. http://webs.uvigo.cs/adesse/). 
a que un verbo sea caracterizado como inergativo o como inacusativo constituye un mero epifenómeno de esa capacidad de los verbos para entrar a formar parte de configuraciones alternativas en la sintaxis (véase, de nuevo, Hernández Paricio, en prensa y Demonte, 2003).

Por tanto, del conjunto de interrogantes antes esbozado acerca de cómo es la relación entre el léxico y la sintaxis parece que la pregunta esencial es la de si cs la configuración sintáctica la que detcrmina la interpretación en términos de papeles semánticos de los argumentos y la interpretación eventiva o aspectual del predicado o si el sentido de la relación es el inverso, como proponen los modelos proyeccionistas. Todo ello es obviamente tema de inevitable (y fructifera) discusión. Son muchas las posturas, amparadas en diferentes modclos de análisis lingüístico, y desgraciadamente no es este el momento de detenerse a hacer siquiera un breve repaso. Lo que sí tiene que quedar claro es que si hay distintas posturas es porque hay muchas cuestiones sin resolver y una de ellas es crucial para el tema que aquí nos ocupa: la de qué sabemos de un verbo cuando lo sabemos. Esto es, qué información contienen los verbos como entradas en el léxico y qué parte de esa información tiene qué consecuencias en la sintaxis.

Aun sin poder dar una respuesta plenamente satisfactoria a esa pregunta, sí parece que se puede afirmar que en las entradas de los verbos en el léxico hay contenida información sobre el aspecto, «el modo en que tiene lugar el evento descrito por un predicado»; esto es, un verbo informa sobre la manera en que se desarrolla y distribuye en el tiempo el evento que denota (De Miguel, 1999: 2979-80). Asimismo, constituye un supuesto básico de la bibliografia sobre aspccto léxico el que se pueden establecer clases de verbos en función precisamente del evento que denotan y que la pertenencia a una u otra clase aspcctual determina las construcciones de las que un verbo va a poder formar parte, los modificadores adverbiales con los que podrá coaparecer y el tipo de fenómenos sintácticos que experimentará ${ }^{19}$. Y, cn cfecto, la bibliografía sobre aspecto, ampliamente desarrollada en las dos últimas décadas, ha permitido dar cuenta de un importante número de fenómenos sintácticos (y morfológicos) que no habían rccibido un análisis adecuado en otros términos y que se explican en cambio si se toman en cuenta las clases aspectuales de verbos (cfr. De Miguel, 1999).

Ahora bien, aunque cl recurso al aspecto ha sido eficaz a la hora de explicar ciertos comportamientos sintácticos de los verbos por su adscripción a una u otra clase aspectual, todavía quedan cuestiones pendientes de explicación que esta perspectiva de análisis no resuelve. Entre otras, como señala Val Álvaro (1999:148), no está explicado, en última instancia, por qué un verbo pertenece a una u otra clase aspectual $\mathrm{y}$, lo que es aún más llamativo, por qué un mismo tipo de evento se puede manifestar por medio de clases de verbos diferentes desde el punto de vista configuracional. Por ejemplo, como ya se mencionó más arriba, un estado se puede expresar a través de verbos atributivos, inacusativos y transitivos (directos e indirectos), lo que indica que no existe una corrcspondencia evidente entre tipos de evento y clases sintácticas de verbos. Tampoco está claro, y esto parece un problema todavía mayor, por qué un verbo puede cambiar de clase aspectual, a veces incluso sin cambiar su configuración en la sintaxis, como se observa en (1), donde se repiten numerados un par

19 En De Miguel (1999: 3045) se incluye un cuadro en el que se recogen algunas de las posibilidades combinatorius de las distinlas clases aspectuales de verbos. 
de cjemplos que ya se han citado en el texto a propósito del verbo llegar y se ofrecen otros pares con verbos sobre los que volveremos más adelante $(\$ 2.3)$ :

(1) a. El atleta llegó hasta la playa la semana pasada

b. La carretera llegó hasta la playa la semana pasada

c. Juan vio el castillo desde el coche

d. Juan vio el castillo hasta las cinco de la tarde

e. El cocinero empezó la tarta sin ayuda del pinche

f. El niño empezó la tarta sin permiso

El ejemplo (1a) representa un predicado de logro, compatible, pues, con los modificadores adverbiales habitualmente utilizados para probar la pertenencia a esta clase aspectual: en treinta minutos, rápidamente, a las seis en punto de la mañana. En cambio, ninguno de estos modificadores podrían coaparecer en el ejemplo ( $1 \mathrm{~b}$ ), que se describe más propiamente como un predicado de estado, en concreto, como un estado que se mantiene desde la semana pasada (parafraseable grosso modo por 'desde la semana pasada hay carretera en la playa' $)^{20}$. Los contrastes de (2) ilustran este comportamiento dispar de un mismo verbo llegar en $(1 a-b)^{21}$ :

(2) a. El atleta llegó hasta la playa fen treinta minutosírápidamentela las seis en punto de la mañana\}

b. H*El atleta llega hasta la playa \{ainidesde la semana pasada\}

c.\#/* La carretera llegó hasta la playa ́en treinta minutos/rápidamenteía las seis en punto de la mañanas

d. La carretera llega hasta la playa\{ain/desde la semana pasada\}

Los datos de (la-b) plantean en efecto una dificultad seria tanto para un enfoque proyeccionista como para uno construccionista. Para el primero de ellos la clase aspectual a la que pertenece un predicado es información léxica que se proyecta en la sintaxis y determina la estructura argumental del verbo; ahora bien, en la medida en que aquí un mismo verbo con los mismos argumentos materializados tiene dos interpretacioncs aspectuales, como se ilustra en (2), un enfoque proyeccionista parece obligado a asumir dos entradas

20 Los términos de logro y estado pertenecen a la bibliografia tradicional sobre aspecto; en concreto, proceden de Vendler (1967), quien distinguió cntre estados (eventos sin dinamismo, sin filal y con duración), logros (eventos dinámicos, sin duración y con final), realizaciones (eventos dinámicos, con duración y final) y actividades (eventos dinámicos, con duración y sin final). En $\$ 2.2$ infra se incluye una propuesta de clasificación eventiva que propone la existencia dc otras posibilidades, algunas de las cuales llevan también el nombre de estado y el de logro. A cfectos de los ejemplos de (1), es indiferente cl sentiđo que se le dé a estos términos, pero véase \$2.2. para las diferencias entre la propuesta de Vendler y la clasificación que aquí se dcficnde.

21 FI signo que precede a (2b), en altemancia con el asterisco, indica que existe una interpretación en la que el ejemplo resulta aceptable, aunque no es la que aquí nos interesa: es aquella en que se entionde el evento de llegar aín como habitual, con una lectura repetida próxima a 'sigue llegando uno y otro día hasta la playa'; un adjunto del Lipo mientras no venga el mal tiempo favorcccría csa interpretación que para algunos informantes es muy evidente. También algunos hablantes pueden interpretar (2c) con el sentido incoativo de «pasó a haber», de ahi el signo que precede al ejemplo en alternancia asinismo con el asterisco que indica su inaceptabilidad an el sentido de (2a). 
en el léxico. ${ }^{22}$ Con todo, esas dos hipotéticas entradas para dos verbos homónimos llegar codificarían en teoría distinta información léxica pero proyectarían una misma configuración, por lo que de nuevo este tipo de análisis se enfrentaría a un problema, como poco de redundancia, pero seguramente también de fundamento.

Por su parte, un enfoque construccionista no puede explicar tampoco cómo es que una misma configuración sintáctica se interpreta aspectualmente de distinto modo ${ }^{23}$. Si se supone que los verbos en el léxico no contienen información sobre el número y la realización sintáctica de sus argumentos sino que es la configuración en la que entran la que determina la interpretación aspectual del predicado, no se explica por qué un mismo verbo en una misma configuración desencadena interpretaciones aspectuales distintas. Por tanto, los datos de (1ab) plantean también un problema de fundamento para un enfoque sintactista, que sólo podría salvarse, hasta dónde yo sé, recurriendo a especificaciones idiosincrásicas en las correspondientes entradas léxicas, procedimiento que no sólo daría tratamiento de irrcgular a un procedimiento general y productivo en las lenguas sino que además vulneraría el sentido de lo que es una conccpción construccionista (o neo-construccionista) del estudio gramatical.

Los pares de (1c-d) y (le-f) reflejan igualmente cómo predicados idénticos (o, al menos, muy similares) en sus requisitos configuracionales, manifiestan diferencias interpretativas (no exclusivamente aspectuales) con consecuencias sintácticas, como ilustran los ejemplos de $(3 a-b)$ y $(3 c-d)$; en un caso la pasiva es posible - $(3 b)$ y $(3 c)-$ y en otro resulta muy forzada o imposible - (3a) y (3d)--, comportamiento en apariencia extraño que es preciso explicar y que, en principio, no parece poderse derivar de la información aspectual de una manera sencilla y directa:

(3) a. ?" El castillo fue visto por Juan desde el coche

b. EI castillo fue visto por muchos turistas hasta las cinco de la tarde

c. La tarta fue empezada por el cocinero sin ayuda del pinche

d. ??HLa tarta fue empezada por el niño sin permiso

En suma, los ejemplos de (1) muestran, por un lado, que el establecimiento del aspecto léxico de un verbo no parece una condición ni necesaria ni suficientc para derivar su estruc-

22 Esta manera de operar supondría un enriquecimiento excesivo del léxico, dado que lo ilustrado en (1) es un hecho regular en los verbos de todas las lenguas. En De Miguel y Fernández Lagunilla (en prensa) se pasa rcvista a un conjunto de datos que muestran cómo en efecto distintas inlerpretaciones aspectuales de un mismo verbo pucden estar ligadas a idénticas configuraciones sintácticas, e incluso casos en que un mismo predicado (con no sólo el misno verbo sitro también con los mismos argumentos y adjuntos) se puede interpretar aspectualmente de distinta manera: por ejemplo, el niño hlega hasta el botón del ascensor, oración que se puede interpretar como un predicado dinámico de logro, que ocurre en cierto punto en el tiempo ('en este momento, el niño llega...'), o cotno un predicado estático, que describe la altura del niño (parafraseable grosso modo por "hay niño hasta esa altura'). En consecuencia, habria que duplicar y aun triplicar las cntradas, lo que complica no sólo la explicación del lingüista sobre cómo está organizado el léxico sino, lo que es más importante, el proceso de adquisición por parte del niño (cfr. Pustejovsky y Boguracv, 1993 y Pustejovsky y Bouillon,1996). La cuestión de las distinciones aspectuales está muy presente en los trabajos sobre adquisición, tanto desde un punto de vista tcórico (Sanz, 2000; van Hout, 2002) como desde uno más aplicado (Sanz y Fukushima, 2003; Diaz et alii, 2003), dado el carácter determinante que se les atribuye en los procesos sintácticos y morfológicos.

23 En Val Alvaro $(2003: 8)$ se menciona también la dificultad que plantea para un análisis construccionista un dato como el agua llegó a las casas, configuración que se corresponde con la de las construcciones transitivas y con las estructuras eventivas de realización, cuando no es ninguna de las dos cosas. 
tura argumental; $y$, por otro, que hay diferencias aspectuales que derivan de informaciones no visibles que será preciso explicitar. Parece, pues, que se hace preciso recurrir a algún otro tipo de explicación, complementaria o alternativa ${ }^{24}$. La explicación que se proponga deberá deducirse de una hipótesis que establezca con nitidez los principios scmánticos en torno a los cuales se organizan las clases verbales. Como establece Cifuentes (1999), a propósito del espinoso asunto de la inacusatividad o inergatividad de los verbos de movimiento ${ }^{25}$ :

Dado que las clases de verbos se organizan de muy diferentes formas según su comportamiento sintáctico en distintas lenguas, esta clasificación sugiere que las clases de verbos no son primitivos, sino que surgen porque sus miembros comparten ciertos componentes básicos de significado. [...] cualquier representación semántica léxica que se adopte debe ser capaz de acomodar las propiedades de los verbos y las clases a las que pertenecen. (Cifuentes, 1999:56)

En consecuencia, necesitamos una representación léxica de los verbos que dé cuenta de sus propiedades combinatorias y permita agruparlos en clases; que explique por qué algunos de ellos cambian en ocasiones sus requisitos de selección y subcategorización y por qué en ocasiones un mismo verbo, con una misma configuración, se adjudica a clases aspectuales distintas. Dedico a ello la próxima sección.

2. Cómo se estructuran las entradas de los verbos en el léxico y Cómo se altera su estructuración. Propuesta ck tírminos de la Estructura Eventiva y la Estructura de Qualia DF. J. PusteJovsky

En este apartado presento una propuesta de clasificación de los verbos que atiende al tipo de evento que denotan y que ya ha sido argumentada y justificada en una serie de trabajos previos $^{26}$. Si la propuesta es válida, ha de permitir predecir al menos en parte los requisitos de selección de complementos y sujeto de los verbos, su comportamiento frente a fenómenos sintácticos y morfológicos, sus interpretaciones y aun sus extensiones de significado en determinados contextos ${ }^{27}$. La propuesta de clasificación verbal (así como los principios que

24 En De Miguel y Fornández Lagunilla (2004) y Fernández Lagunilla y De Miguel (en prensa) se analizan otra serie de fenómenos relacionados con la predicación secundaria y la modificación adverbial que muestran también una evidente relación con la información aspectual pero que exigen, para ser explicados adecuadamente, un análisis que tome cn consideración otro tipo de información; nuestra propuesta alli, como aquí, es que la explicación de estos fenómenos mejora si se recurre a la información contenida en lo que Pustejovsky (1991 y siguientes) Ilama la Estructura de Qualia. de la que en seguida se hablará en el texto (cfr. \$2.1.1.)

25 Para el autor, es precise un estudio semántico (en su hipótesis, de índole cognitiva) que explique mediante rasgos scmánticos el distinto comportamiento de la clase de los verbos de movimiento, sean estos transitivos o intransitivos. En su opinión, «una vez que la representación semántica léxica apropiada sea desarrollada, y los aspectos del significado relevantes en la determinación de las clases de verbos de movimiento aislados, mucho del aparentemente caótico comportamiento de estos verbos podrá recibir un análisis más detallado» (Cifuentes, 1999:56).

26 En efecto, la propuesta se ha justificado y argumentado, matizado y refinado a to largo de los siguientes trabajos en colaboración: Fernández Lagunilla y De Miguel (1999, 2000a, 2000b y en prensa) y De Miguel y Fcrnández. I agunilla (2000at, 2000b, 2004 y en prensa). También se hace uso de ella en De Miguel (2000) y en De Miguel (en prensa).

27 Y eso es lo que se ha perseguido en los trabajos moncionados en la nota anterior. 
dan cuenta de las aparentes «irregularidades» o «excepciones» de la clasificación) se inscribe dentro de un modelo teórico novedoso y sugerente, la Teoría del Lexicón Generativo de Pustejovsky $(1991,1993,1995,2000)$, cuyos principios y supuestos básicos se recogen en el primer apartado de esta sección (\$2.1.). En \$2.2. se recoge la propuesta de clasificación verbal inspirada en Pustejovsky. En $\$ 2.3$. se incluye una propuesta de análisis de un par de verbos en términos de la clasificación propuesta en $\$ 2.2$. y se formula de modo explícito la hipótesis de que la información contenida en la Estructura Eventiva (criterio en el que se ha basado la clasificación verbal) y la información recogida en la Estructura de Qualia interactúan y su interacción permite explicar ciertas extensiones del significado de los verbos. El §2.4. es el apartado de las predicciones, donde se recupera una cuestión interesante relacionada con los vcrbos de soporte y las extensiones metafóricas que puede investigarse en términos de infraespecificación (concepto que en seguida se definirá, cfr. \$2.1.) y se avanza una hipótesis explicativa del tradicionalmente esquivo comportamiento de las pasivas con estar y el llamado complemento agente.

\subsection{La Teoría del Lexicón Generativo (Pustejovsky, 1991, 1995, 2000)}

La Teoría del Lexicón Generativo recibe este nombre porque es concebida por su autor como un modelo que atribuye capacidad generativa al léxico. Es decir, para Pustejovsky el léxico no constituye un componente estático - en el que aparecerían cnumerados los signos lingüísticos con lo que podríamos llamar su definición de diccionario-, sino que es un nivel organizado de acuerdo con una teoria rica y recursiva de descomposición del significado, que acoge gran parte de la potencialidad significativa y creativa del lenguaje.

Esa manera de concehir el léxico le va a permitir a Pustcjovsky dar cuenta de algunos problemas básicos del estudio léxico-sintáctico (relaciones entre estructura de evento y estructura sintáctica, tipos básicos de predicados y alternancias de estos) y, muy especialmente, de ciertos aspectos del lenguaje natural hasta ahora no explicados o insuficientemente explicados por la semántica compositiva, en especial el problema de la polisemia de las unidades léxicas: cómo es que somos capaces de atribuir un número potencialmente infinito de sentidos a las palabras en contexto, con un número limitado de recursos. Es decir, cómo se explica, sín relcgar la explicación al terreno del saber enciclopédico o el conocimiento del mundo, que la palabra excelente predicada de un cuchillo o de un profesor signifique 'que hace muy bien su función', pero predicado de una persona o de una cabellera signifique "que tiene cierto tipo de cualidades', como se ve en (2) (véase a este respecto, Bosque, 1997):

\section{(4) a. Un \{profesor/cuchillo\} excelente b. Una \{personaicabellera\} excelente}

Uno de los conceptos básicos del modelo de Pustejovsky es el de la infraespecificación, que se puede definir informalmente como en (5):

(5) Infraespecificación (underspecification): Falta de especificación de los signos lingïisticos que los capacita para intervenir en diferentes estructuras sintácticas y, en consecuencia, en distintas operaciones de composición semóntica'. (Cfr. Pustejovsky, 1995) 
Según Pustejovsky, el nivel léxico contiene entradas léxicas infraespecificadas que subsumen los posibles sentidos que una palabra puede adquirir en el contexto (lo que él llama la polisemia lógica). De este modo se hace innecesario enumerar los múltiples sentidos de una misma palabra y se da cuenta de la rclación sistemática que existe entre estos. Así, la entrada léxica de una palabra como novela contendrá información potencial que la capacita para significar una cosa en (6a) y desencadenar en cambio dos interpretaciones en (6b) y (6c):

(6) a. He comprado la novela

b. He empezado la novela (= 'he empezado a \{leenla'escribirla\}')

c. He acabado la novela (= 'he acabado de \{leerla/escribirla\}')

Esa información potencial sobre las características que definen una unidad léxica — del tipo de «es un objeto preexistentc que puede cambiar de propietario», en (6a); «es un objeto que se crea a través de una actividad, como la de escribir», en (6b-c); o «es un objeto preexistente destinado normalmentc a ser leído», en (6b-c)-, información que permite predecir su comportamiento sintáctico, está contenida en cuatro elementos del significado que el autor denomina roles o qualia, y que son el constitutivo, el formal, el télico y el agentivo. La representación estructurada de esos cuatro aspectos esenciales del significado de una palabra (lo que Pustejovsky denomina la Estructura de Qualia) proporciona la fuerza relacional de una pieza Iéxica y determina no sólo el significado de ciertas combinaciones, sino también la posibilidad de que ciertas combinaciones se den o no.

\subsubsection{La Estructura de Qualia (Qualia Structure)}

En cste nivel de representación se imbrican las Estructuras Argumental y Eventiva proporcionando un armazón sobre el que aplicar mecanismos generativos y transformaciones semánticas, que altcren la denotación de una pieza léxica dependiendo del contexto en que se inserte. En (7) se recogen los cuatro tipos de quale propuestos por Pustejovsky:

(7) a. Quale constitutivo, que codifica la relación entre un objeto y sus partes constituyentes, asi como la relación entre una entidad y aquella entidad compleja de la que es parte (es decir, información sobre el material, peso, partes y elementos componentes).

b. Quale formal, que codifica aquello que distingue el objeto dentro de un dominio más extenso (es decir, información sabre la orientación, magnitud, forma, dimensionalidad, color y posición).

c. Quale télico, que codifica el propósito y función del objeto (es decir, información sobre el propósito que un agente tiene al realizar un acto o producir un objeto, o el propósito especifico de cierias actividades, su función inherente).

d. Quale agentivo, que codifica factores implicados en el origen o producción de un objeto (es decir, información sobre el creador, el artefacto, la clase natural o la cadena causal que ha desencadenado su existencia).

Pustejovsky ilustra cómo se codifican estas cuatro informaciones en el caso de la palabra novela atribuyéndole la selección de qualia recogida en (8): 
(8) a. quale constitutivo - narrativa

b. quale formal - libro $(x)$ c. quale télico - leer $(e I, y, x)$

d. quale agentivo - escribir $(e 2, z, x)$

La hipótesis de que la entrada léxica de las palabras contiene estos «aspectos esenciales de su significado» — que informan sobre propiedades particulares de los nombres (y los SSNNN que los contienen) y sobre actividades a ellos asociadas - permite resolver ciertos fenómenos relacionados con la polisemia de las palabras que, de no contar con procesos de selección de qualia, exigirian incluir en el léxico diversas entradas para un mismo vocablo. En estos términos, la polisemia de excelente en (4) adquiere una explicación sencilla y económica: en (4a) el adjetivo materializa el quale télico del nombre (aquello para lo que está destinado) y en (4b) el constitutivo (la información sobre su constitución interna).

Así reciben también explicación ciertos casos de ambigücdad normalmente atribuidos a inferencias culturales, procedentes del conocimiento del mundo. Por ejemplo, la que se da en (6b) y (6c) a propósito de la novela: en ambos casos se puede sobreentender 'a escribirla', cuando se selecciona el quale agentivo del nombre, o 'a leerla', si se selecciona el quale télico. La adecuada selección (determinada por el contexto) de la información codificada bien en el rol télico bien en el agentivo capacita a oraciones como las de (6b-c) para recibir una u otra de las paráfrasis alternativas rccogidas entre paréntesis. Fs decir, a través de los qualia el verbo adquiere en (6) la información requerida para contextualizar el sentido de empezar, lo que indica que se trata de una información léxica que penetra en la sintaxis; y de forma regular y productiva, como ilustra el que si en un predicado como los de (6) aparece el llamado se (me, te) culminativo o clítico culminativo - en términos de De Miguel y Fernández Lagunilla (2000)--, la única interpretación posible es la desencadenada por la selección del quale télico, como se ve en (9):

\section{(9) a. Me he (empezado/acabado\} la novela b. Me dejé la novela a la mitad}

En efecto, (9a) implica necesariamente 'a leer/de leer', no 'a/de escribir'. Según De Miguel y Fernández Lagunilla (2000), el me (te, se...) de (9) es un operador aspectual que indica que el evento ha culminado y ha dado paso a un estado nuevo. Pues bien, esta caracterización del clítico culminativo exige que el evento se predique de un objeto precxistente (que pueda cambiar de estado), por lo que resulta incompatible con el quale agentivo. El quale agentivo, en la modida en que codifica información sobre cómo llega a cxistir un objeto, no implica su existencia previa. El quale télico, que codifica para qué sirve o se usa un objeto, sí prcsupone la existencia del objeto del que se predica el cambio de estado. Por tanto, será la información del quale télico la única compatible con el clitico culminativo. Y así es: el mismo efecto se observa en casos como (9b), que implica 'abandoné su lectura', no 'su escritura' (véase a este respecto González Muñoz, 2003).

Este modelo de léxico generativo de Pustejovsky, que, como homos visto, intenta describir cómo se generan los diversos sentidos de las palabras en lugar de limitarse a enumcrarlos, y que propone entradas léxicas infraespecificadas capaces de tomar, dependiendo del contexto oracional, uno de entre una multiplicidad de sentidos interrelacionados, proporciona instrumentos muy interesantes para explicar una scrie de relaciones semánticas regulares y productivas que se dan en todas las lenguas y que las explicaciones tradicionales han relegado a menudo al terreno del saber enciclopédico y del conocimiento del mundo por 
parte de los hablantes por considerarlas fenómenos idiosincrásicos, irregulares y de dificil sistematización ${ }^{28}$. Se trata de las cxtensiones de significado que la bibliografia habitual ha consagrado con los nombres de metáfora, metonimia, hiperonimia e hiponimia, polisemia y meronimia, entre otras ${ }^{29}$. Son todos casos en que una palabra o una expresión ha ampliado su significado de forma tal que el enunciado en que se encuentra no se interpreta de forma literal. A pesar de ello, no constituyen fenómenos particulares ni irregulares sino generales a todas las lenguas y muy productivos, y las expresiones a que dan lugar no plantean dificultades al hablante nativo a la hora de descodificar su significado. En consccuencia, un modelo explicativo de la organización del léxico y de las operaciones que tienen lugar en ese nivel ha de proponer mecanismos que expliquen cómo pueden las palabras ampliar su significado y cómo pueden los hablantes entender los nuevos significados.

La Teoría del Lexicón Generativo establece un conjunto de principios que controlan las condiciones de buena formación de los sintagmas y las oraciones y captan la relación semántica entre las unidades que los componen, y que permiten explicar el hecho de que existan extensiones de significado regulares y productivas a pesar de su aparente idiomaticidad. Entre esos principios se encuentran el de combinación y selección de tipos o Ligamiento Selectivo, el de Coerción o Coacción de Tipos ${ }^{30}$ y el de Cocomposición, operaciones que pueden variar el tipo inicialmente asociado a una entrada léxica según el contexto en que esta entre. He incluido en (10) una breve definición de cada uno de estos principios.

(10) a. Coacción de Tipos (Type Coercion): mecanismo que se produce cuando una pieza léxica o un sintagma es coaccionado por un núclen rector en el sintagma para interpretarse semánticamente de una delerminada manera, sin cambiar su tipo sintáctico. Ejemplo: cuando un verbo del tipo de empezar (núcleo rector), que selecciona semánticamente un evento en la posición de objeto, se construye con un complemento como novela. Dado que novela es de tipo objeto, empezar fuerza un cambio de tipo semánico en novela, de objeto a evento, con lo que se obtienen interpretaciones como las de (6), posibles gracias a que el quale télico de novela es el predicado leer y el quale agentivo es escribir.

b. Ligamiento Selectivo (Selective Binding): mecanismo que se produce cuando una pieza léxica o un sintagma opera especificamente sobre una subestructura de una representación, sin cambiar el tipo general de la composición. Ejemplo: en casos como subir permite que se opere sobre una subesiructura, con la consecuencia de que se pueden obtener dos interpretaciones, la causativa (el gobierno sube el precio de la gasolina) y la inacusativa (el precio de la gasolina sube).

c. Cocomposición (Ca-composition): mecanismo que se produce cuando múitiples elementos dentro de un sintagma se comportan como functores (no sólo uno de ellos, como el verbo, que es lo habitual), y generan con su actuación conjunta mevos sentidos no lexicalizados para las palabras que intervienen en la cocomposición. Ejemplo: un predicado como hacer en el horno (que significa 'manera de cocinar': \{hacer en el horno/hacer a la plancha/hervir/freír\} un pescado $e$ implica un cambio

28 Con independencia de su acierto o no a la hora de explicar cómo está organizado cl lćxico, cuestión que es objeto de polćmica (cfr., por ejemplo Fodor y Lepore, 1998).

29 A propósito de la meronimia desde una perspectiva que aúna el modelo cognitivo y la Teoría del Lexicón Generativo, véase Climent Roca (2000). También en De Migucl (2003) se aborda la meronimia con un análisis inscrito en el modelo de Pustejovsky.

30 También denominado Modificación del Tipo Denotado, de acuerdo con la propuesta de Bosque (1997). 
de estado en el objeto) adquiere el significado de 'crear' cuando se combina con el bizcocho, cl soufflé (entidades que no preexisten, como el pescado, sino que se crean a través del homo), gracias al mecanismo de cocomposición entre hacer cn el horno $y$ \{bizcocho, soufflć\}; este mecanismo se desencadena a causa de la identidad de valores en uno de los roles de la Estructura de Qualia de los dos participantes en la composición (el agentivo, en ambos casos).

La aplicación de estas reglas o principios de bucna formación semántica está condicionada por el contexto sintáctico-semántico en que aparece la pieza léxica y por cso Pustejovsky defiende que es imposible separar el significado de la estructura sintáctica que lo contiene; en ese sentido la propuesta de Pustejovsky integra supuestos del proyeccionismo y del construccionismo. Pensemos en un ejemplo en cl que intervienen los mecanismos de coacción y cocomposición, por ejemplo, en el predicado incluido en (11):

\section{(11) Maria quiere una taza de café}

El verbo querer en (11) exige un complemento eventivo, por lo que coacciona al nombre que le acompaña para denotar un evento: beber o tomar. El evento seleccionado requiere un argumento de tipo 'líquido' y taza no lo es. Sin embargo, la construcción es perfectamente interpretable: se supone que café ha coaccionado a su núcleo taza para dejar de referirse al continente y pasar a expresar el contenido, la dosis o cantidad de café que cabe en el recipiente. Coaccionada la palabra taza para significar 'dosis' y taza de café capacitada para referirse a un evento, a través del quale télico (beber), se produce la cocomposición y el predicado se interpreta de manera adecuada. Fste tipo de fenómeno, metonimia por un lado, sinestesia por otro, es un fenómeno regular y productivo, dado que en todas las lenguas en las que los hablantes dicen beber tazas, se refieren en realidad a los líquidos contenidos en las tazas, y en general cuando se quiere una taza de café, a menos que se especifique otra cosa o cl discurso permita otro tipo de recuperación, se entiende que se quiere beber (y no comprar o romper) la taza. Pues bien, como vemos, los mecanismos propuestos por Pustejovsky y recogidos en (10) permiten explicar estos y otros fenómenos de un modo innovador, que resulta sumamente atractivo y prometedor.

Aparte de esta información potencialmente recogida en los cuatro roles que según Pustejovsky componen la Estructura de Qualia de las palabras, el autor propone que las entradas léxicas contienen también información sobre su Estructura Argumental y sobre su Estructura Eventiva. La Estructura Argumental especifica el número y cl tipo de argumentos lógicos que posee un elemento léxico, y también, cómo se realizan esos argumentos sintácticamente. Los argumentos lógicos son, por una parte, los argumentos obligatorios, de realización sintáctica obligatoria, y, por otra, los argumentos de realización opcional, entre los que se encuentran los argumentos defectivos y los sobrccntendidos. La estructura argumental incluye también los adjuntos lógicos, que son parámetros que forman parte de la interpretación situacional y que modifican la expresión lógica, pero que no están ligados a una representación semántica concreta del elemento léxico. A este grupo pertenecen las exprcsiones de modificación temporal o espacial. A la Estructura Eventiva le dedico el próximo apartado.

La información contenida en las distintas estructuras interactúa a través de los principios y mecanismos arriba mencionados y su interacción resulta determinante a la hora de 
interpretar las palabras en un contexto determinado y a la hora de entender ciertos procesos sintácticos que no parecen recibir explicación si se atiende a las informaciones parcialmente contenidas en cada una de las estructuras por separado ${ }^{31}$.

\subsubsection{La Estructura Eventiva (Event Structure)}

En esta estructura se indica el tipo de evento denotado por una pieza léxica o por un sintagma. Pustejovsky propone que los eventos no son entidades atómicas, sino que están dotados de una estructura interna y, por tanto, se pueden descomponer en diferentes fases o subeventos. Las clases de eventos según el autor son estados, procesos y transiciones y su estructura interna o subeventiva es la recogida en (12).

(12) Esquema 1: Tipos de evento según Pustejovsky (1991, 1995)

a. Estado (E):

Evento simple, que se evalúa sin ponerlo en relación con otros cventos; por cjemplo: amar, saber, pensar.

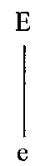

b. Proceso (P):

Sucesión de eventos identificados como una misma expresión semántica: correr, Fudar:

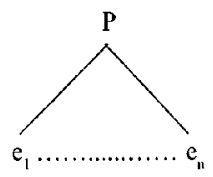

c. Transición (T):

Evento que identifica una expresión semántica, evaluada en relación con su oposición: constmir, destruir.

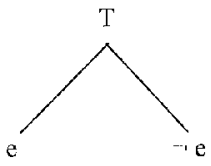

31 Pustejovsky propone un cuarto nivel de representación integrado en las entradas de las palabras en el léxico, la llamada Estructura de Herencia Léxica; dado que la información que codifica no es objeto de interés en este trabajo, renuncio a hacer una presentación, ni siquiera breve, de su contenido. El lector encontrará información al respecto en los distintos trabajos de Pustejovsky citados en la bibliografía (y un breve resumen en Vázquéz et alii (2000)). 
En la medida en que una transición implica un proceso que da lugar a un nuevo estado, también se puede representar como:

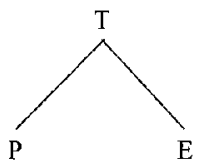

$\mathrm{e}=$ variable para cualçuier tipo de evento

Como ya se adelantó, el esquema de (12) supone una modificación de la clasificación de Vendler (1967), probablemente la de más éxito en la bibliografía tradicional sobre aspecto. Vendler distinguió cuatro tipos de situaciones y propuso una serie de tests lingüísticos para discriminarlas.: estados (eventos sin dinamismo, sin final y con duración; por ejemplo, amar, tener), logros (eventos dinámicos, sin duración y con final; por ejemplo, descubrir, llegar), realizaciones (eventos dinámicos, con duración y final; por ejemplo, romper, construir una. casa) y actividades (eventos dinámicos, con duración y sin final, por ejemplo, nadar, trabajar). Pues bien, como se ve en (12c), la clasificación de Pustejovsky aúna los logros y las realizaciones de Vendler en los eventos de transición; si solo se realiza cl subevento final, el evento es do logro, mientras que si se realiza el evento complejo (compuesto de la fase de proceso y la de logro), entonces constituye una realización ${ }^{32}$. Esto es posible precisamente porque el autor considera que los eventos no son entidades atómicas sino que están dotados de estructura interna; en la Estructura Eventiva se especifican las fases que constituyen el evento (una o más, según el evento sea simple o complejo), el orden en que se prcceden unas a otras y cuál es la fundamcntal (o núcleo eventivo).

\subsection{La propuesta de clasificación verbal de Fernández Lagunilla (1999) y De Miguel y Fernández Lagunilla (2000; en prensa)}

Como acabamos de ver, la propuesta de Pustejovsky permite dar cuenta de las alternancias entre los miembros causativo/inacusativo de un par como hundir/hundirse; el autor atribuye al par una misma estructura eventiva con dos subeventos; si el primer subevento no se materializa (por estar infraespecificado), el evento resultante es el logro de hundirse, mientras que si se materializan las dos fases, se obtiene la realización de hundir. Ahora bien, este tipo de explicación no permite dar cuenta de la estructura eventiva de verbos como llegar, tradicionalmente considerados de logro, pero que no parecen constituir la segunda fase de un evento complejo. De hecho, llegar constituye un evento simple, que empieza y acaba en un punto; esto es, un evento puntual. Hay otros eventos

32 La propuesta de Pustejovsky implica prescindir del parámetro de la duración para distinguir clases de eventos. Son varios los lingüistas que han coincidido en atribuir a este parámetro un carácter cxtralingüístico y no han hecho uso de él para sus clasificaciones. Otros, en cambio, han defendido su condición de criterio distinguidor de eventos. (Véase a este rcspccto De Miguel, 1999: \$ 46.3.2.5.). Ahora bien, en el caso de Pustejovsky, la razion para incorporar los logros a las transiciones y no concederles un estatus independiente parece más bien relacionada con el parámetro de la agentividad, que está ausente en la segunda fase de las transiciones, csto es, en los logros. 
que también ocurren en un punto, como sentarse, marearse, pero dan lugar a un estado nuevo que puede mantencrse durante un tiempo. Y hay eventos que culminan en un punto pero dan paso a un proceso que se puede seguir dando durante un tiempo: es el caso de hervir y oscilar (cfr. De Miguel, 1999). En (13) se ilustra el distinto comportamiento sintáctico de estos verbos (todos ellos de logro) según si son eventos simples (13 a,a') o complejos, $y$, en este caso, dependiendo de si su segunda fase es un cstado $\left(13 \mathrm{~b}, \mathrm{~b}^{\prime}\right)$ o un proceso (13c, c'):

(13) a. Juan llegó \{a las diez/*durante un rato\}

a'. Juan siguió \{*llegado/tllegando\}

b. Juan se mareó a las diez/durante un rato\}

b'. Juan siguió \{mareado/timareándose?

c. El agua hirvió fa las diez/un rato\}

c'. El agua siguió \{thervidahirviendo\}

Los contrastes de (13) muestran, en efecto, que los verbos de (13b) y (13c), como eventos complejos, admiten distintos tipos de modificación adverbial, según la fase que se focalice: si se enfoca el punto en que culminan, aparece un modificador adverbial deíctico, puntual (a las diez) y si se enfoca la fase de estado o proceso subsiguiente, un modificador adverbial durativo (durante un rato). Esta segunda posibilidad está vedada a los logros simples, que sólo denotan el punto de culminación, según se ve en (13a). Por otra parte, en (13b') vemos cómo el evento de marearse admite la perífrasis seguir + participio para señalar la continuidad del estado subsiguiente al punto de culminación del evento ('una vez mareado, Juan estuvo mareado otro rato'). En cambio, excluye la perifrasis de seguir + gerundio, puesto que la segunda fase de la estructura eventiva no es un proccso. Solo se podría interpretar esta construcción con un valor habitual, de repetición (y de ahí el signo que se le ha adjudicado en el juicio sobre su aceptabilidad). En cuanto a (13c'), por el contrario, admite perfectamente la construcción de seguir + gerundio, puesto que al punto de culminación del evento de hervir puede seguir un periodo en que 'el agua está hirvicndo todavía'. En cambio, la perífrasis de participio solo se acepta si el evento de hervir no se entiende como un logro sino como una transición: esto es, como un evento causativo en cl que un sujeto externo hierve el agua y una vez que esto ocurre, esta está hervida, y puede seguir hervida (de ahí el signo que se le ha adjudicado). Ambas posibilidades están excluidas en cl caso del logro puntual de (13a'), puesto que no consta de una segunda fase focalizable por medio de una perífrasis. (A menos que la perifrasis de seguir + gerundio se interprete en un sentido habitual, para lo cual convendría que apareciese algún tipo de adjunto: Juan siguió llegando hasta la playa hasta que vino el mal tiempo; de ahí el signo que se le ha adjudicado en (13a').)

Precisamente para distinguir los logros del tipo de llegar de los logros del tipo de hundirse que Pustejovsky subsume en las transiciones, pero también para distinguir, dentro de los logros del tipo de hundinse, los del tipo de marearse y los del tipo de hervir, es por lo que en Fernández Lagunilla y De Miguel (1999) iniciamos la ampliación de la clasificación eventiva de Pustejovsky; en ese primer trabajo recuperamos la hipótesis vendleriana de que existen eventos puntuales (los logros) que constituyen eventos independientes y que no son la segunda fase de una transición. Los denominamos Ll y los consideramos cventos 
simples. ${ }^{33}$ A su vez, nuestra propuesta tiene en cuenta que existen cventos que culminan en un punto pero van seguidos de una fase subsiguiente, que puede ser un estado (en los L2) o un proceso (en los L3), por lo que acabamos proponicndo tres tipos de logro. Naturalmente, esta clasificación extendida parte del supuesto básico de Pustejovsky (1991, 1995, 2000) de que los eventos constan de estructura interna. Solo asumiendo una representación geométrica de los eventos, se puede llegar a articular los ocho tipos de cvento propuestos. No se descarta, puesto que cl sistema lo permite, que existan otras posibilidades eventivas. En Fernández Lagunilla y De Miguel (1999) se presenta por primera vez la propuesta pero es en De Migucl y Fernández Lagunilla (2000) donde aparecen por primera vez los ocho tipos de eventos propuestos; en De Miguel y Fernández Lagunilla (en prensa) se incluye la última modificación reseñada acerca de los logros simples. La propuesta que aquí se recoge intenta dar cuenta de ciertos comportamientos sintácticos muy regulares que en la bibliografía habitual se han puesto en relación con el aspecto léxico y que permiten establecer clases aspectuales de verbos más o menos estables (de acuerdo con los parámetros sobre aspecto léxico señalados en De Miguel, 1999). Pero, como ya he dicho, no se descartan otras posibilidades $^{34}$. En (14) se recogen los ocho tipos de evento en su última versión ${ }^{35}$ :

33 La modificación propuesta en De Miguel y Fernández Lagunilla (en prensa) pasa a considerarlos eventos compuestos de dos fases, in que permite explicar su comportamiento sintáctico ante distintas construcciones: entre otras, ante la perífrasis de gerundio progresiva, que admite con interpretación de conato (por ejemplo, Juan está llegando, con el sentido de (está a punto de llegary). En esta versión, pues, llegor es un evento compucsto de una fase en la que no se da un estado y otra en la que si se da el nuevo estado. Es, entonces, una transición entre dos fases ("no estar aquí > estar aquí). De este modo, el catálogo de cvcntos simples queda reducido a los estados y a los procesos (si estos no se consideran transiciones, a la manera en que hace Moreno Cabrera, 1997). Fn la última vcrsión de la propuesta de Fernández Lagunilla y De Miguel, los logros puntuales (L1) se diferencian de los complejos (L2, L3) en que estos constan de dos fases distintas $(<\mathrm{L}, \mathrm{E}\rangle,<\mathrm{L}, \mathrm{P}>$ ), y al menos una de las fases es un logro (por tanto, un evento complejo a su vez; $\mathrm{L}<\neg \mathrm{E}, \mathrm{E}>$ ). Por tanto, siguen manteniendo una distinción, como parece obligado, dadas sus evidentes diferencias sintácticas.

Bjerrc (1999) coincide en proponer una diferencia entre los logros que lorman parte de una estructura compleja (serían el segundo subevento, el estado, de una estructura de transición en línea con Pustejovsky) y otros eventos, estos si puntuales y simples, no integrados en una estructura eventiva superior, a los que è denomina sucesos (happenings). El autor ofrece datos rclacionados con los verbos de soporte que apoyan esta dislinción. A saber: un nombre de suceso, como beso, golpe o bofetada, combinado con un verbo de soporte (dar un beso, una bofetada, un golpe) da lugar a un verbo puntual; en cambio, nombres que denotøn estados como segunda fase de una transición, como oportumidad, fuerzas, ánimos, combinados con verbos de soporte, dan lugar a eventos incoativos (dar una oportunidad), durativos (dar fuerzas), causativos (dar ánimos), etc., es decir, desencadenan diferentes especificaciones aspectuales y un comportamiento sintáctico diferenciado también. Se formule, pues, en los términos quc se formule, parece obligado discriminar diferentes clases de eventos de logro.

34 De hecho, en De Miguel (2000) se propone un tipo cventivo más para explicar el conportamiento de la pesiva con estar en español.

35 No es este el momento de justificar esta clasificación. El lector encontrará la propuesta suficientemcntc argumentada y justificada en el conjunto de trabajos citados en la nota 26 supra. La propucsta se ha aplicado a la explicación de diversos fenómenos relacionados con la cuantificación y la modificación adverbial, con la predicación secundaria, con la pasividad y con las extensiones metafóricas del significado de los verbos, entre atros. Asimismo, las representaciones formales del Esquena 2 infra, establecidas por De Miguel y Fernández Lagunilla a partir de datos del español, han sido defendidas para distintas lenguas (ruso, japonés, italiano, rumano entre otras). Véase, por ejemplo, Batsiukova (en prensa 1; en prensa 2) y Tokunaga (2001), Puede consultarse asimismo la revisión crítica de Moreno Cabrera (2003), donde el autor pasa revista a esta y otras clasificaciones de los eventos verbales, algunas clásicas y otras muy recientes. 
(14) Esquema 2: Tipos de evento seguin De Miguel y Fernández Lagunilla 2000; en prensa)
a. Estado
b. Proceso
c. Transición (T1)
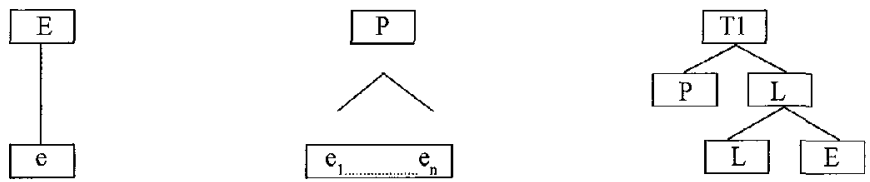

\begin{tabular}{|c|l|l|}
\hline $\begin{array}{l}\text { evento simplc, con duración } \\
\text { y sin fases } \\
\text { (tener, detestar) }\end{array}$ & $\begin{array}{l}\text { secuencia de eventos idénticos, con } \\
\text { duración y fases: evento no delimitado } \\
\text { (estudiar; nadar) }\end{array}$ & $\begin{array}{l}\text { proceso o actividad que desemboca en un } \\
\text { punto seguido de un cambio de estado: } \\
\text { evento delimitado con duración que } \\
\text { culmina en la frase final } \\
\text { (leer un tibro, ver la pelicula) }\end{array}$ \\
\hline
\end{tabular}

\section{d. Logro simple (L1)}

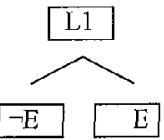

\section{e. Logro compuesto (L2)}

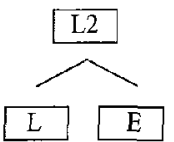

f. Logro compuesto (L3)

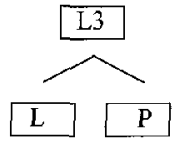

evento delimitado, que ccurre en un punto

(explotar, llegar, nacer) evento delimitado que culmina en un punto (lit fase inicial) y va seguido de un estado

(marearse, ncultarse, sentarse) evento delimitado que culmina en un punto (la fase inicial) y va seguido de un proceso (hervir, forecer; ver la costa)

\section{g. Transición (T2)}

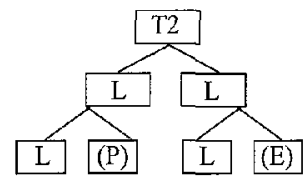

h. Proceso (P2)

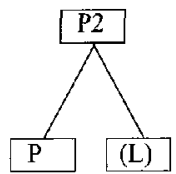

evento delinitado, que implica una transición entre dos puntos de culminación; tarto el subevento inicial como el final pueden a su ver. descomponerse en dos fases (aparecer(se), bajar(se), caer(se), ir(se), morir(se), subir(se), wenir(se), volver(se)) evento incrementativo o de acabamiento gradual

(adelgazar, engordar, encanecer, envejecer)

$c=$ variable para cualquier tipo de evento

\subsection{La definición infraespecificada de ver y de llegar. Propuesta de análisis en términos de la Estructura Eventiva y la estructura de Qualia}

En esta sección, me propongo dar cuenta de los datos recogidos en (1) que, como se recordará, plantean un problema tanto para un enfoque de tipo (neo)construccionista como para un modelo proyeccionista. El análisis que defiendo se basa en los principios de la Teoria 
del Lexicón Generativo recogidos en (10) y especialmente recurre a la información codificada hipotéticamente en la Estructura Eventiva (EE a partir de ahora) y en la Estructura dc Qualia (EQ a partir de ahora).

\subsubsection{Los supuestos básicos de la hipótesis en que se basa el análisis de los verbos en términos de su EE y su $E Q$}

A lo largo de $\$ 2$ he presentado cómo concibe Pustejovsky la EE (el nivel donde se codifica información sobre la estructura interna del evento denotado por un predicado) y la EQ (nivel donde se codifica información de tipo subléxico sobre el modo en que un evento llega a darse, el propósito con que ocurre, etc.). Los argumentos que participan en el evento denotado por el verbo son refcridos por nombres que también contienen en sus respectivas EEQQ información del tipo mencionado. La adecuada cocomposición entre las informaciones de uno y otros permite construir estructuras aceptables e interpretables. Como se ha mencionado también, en ocasiones la cocomposición parece excluida en principio. Cuando la cocomposición no puede darse porque la información del nombre no permite satisfacer los requisitos de selección del verbo, la estructura no es interpretable a menos que opere un mecanismo previo de coacción o modificación de los rasgos; si el núcleo rector coacciona los rasgos del nombre que selecciona, se puede entonces producir una cocomposición adecuada: son los casos en que se producen extensiones de significado, a menudo consideradas metafóricas o metonímicas, perfectamentc regulares e interpretables por parte de los hablantes, como ya se mencionó a propósito de (11).

El análisis que a continuación voy a proponer suscribe la hipótesis de que los verbos (de hecho, todas las palabras, sea cual sea su categoría gramatical, pero aquí nos interesan los verbos) cuentan con un significado básico, en parte codificado en la EE y en parte en la $\mathrm{EQ}$. $\mathrm{Y}$ asume asimismo que los nombres que constituyen los níclcos de los sintagmas quc componen la estructura argumental del verbo tienen también un significado básico en parte codificado en la EQ. La idea fundamental en torno a la cual gira el análisis es la de que ese significado básico del verbo está infraespecificado, en el sentido de "potencialmente capacitado para adquirir distintos significados en contexto' -recuérdese la definición de infraespecificación recogida en (5) - Esa potencialidad se materializa en combinación con los argumentos: más propiamente, en adecuada cocomposición con la información contenida en la EQ de los nombres, en ocasiones previa intervención de un mecanismo de coacción.

Además de suscribir estos supuestos básicos, mi propuesta de análisis da por sentada asimismo la adecuación de las clases de eventos recogidas en (14), puesto que no es mi objetivo en las páginas que siguen defender una u otra clasificación de los verbos por su aspecto. Antes bien, el propósito de este trabajo es el de argumentar a favor de la posibilidad de que las distintas informaciones contenidas en la definición de diccionario de las entradas léxicas (bien en su EE bien en los cuatro roles de la EQ) interactúen de un modo tal que la complejidad de los datos de (1) y las dificultades que plantean tanto a una explicación lexicista como a una sintactista se resuelvan apropiadamente. Con esta hipótesis parecen recibir explicación cicrtos procesos sintácticos de los que no da cuenta un análisis que atienda sólo a la clase de eventos que en ellos participan, entre otros el aparentemente extraño comportamiento de la formación de pasivas en español con los verbos transitivos 
de (lc-f) y la distribución de los adverbios aspectuales y las perífrasis de gerundio con el verbo intransitivo de (la-b).

La hipótcsis de que la EQ de los argumentos puede influir en la especificación del tipo de evento se asienta asimismo de manera fundamental en el supuesto de que los eventos están dotados de una estructura interna, geométrica. Sólo si se considera que los eventos denotados por los verbos no constituyen entidades atómicas, compactas, sino que son unidades articuladas, que pueden estar compuestas de sub-eventos, se entiende que la presencia de un dcterminado adjunto o las características subléxicas de los argumentos puedan influir en su $\mathrm{EE}$, sumándole o restándole fases, es decir, volviéndola más simple o más compleja. A su vez, esta concepción articulada de la entrada léxica permite reducir drásticamente el número de entradas diferentes que se postulan en el léxico para dar cuenta de significados distintos pero relacionados de una misma palabra; y además explica cn qué medida se puede defender que el contexto varíe la definición aspectual de un predicado.

Desde esta perspectiva, no es que la sintaxis determine la interpretación (como propondría un modelo (neo)construccionista); es que dentro del propio léxico están recogidas las potencialidades de materialización de un predicado en virtud de la cocomposición con la información de las palabras que son sus argumentos. Es decir, la propuesta de análisis que aquí se defiende se inserta dentro de un modelo proyeccionista que integra no obstante la variación contextual en la medida en que prevé la infraespecificación de las definiciones. Cuanto menos infraespecificada está una palabra, más potencialidades manifiesta y también, por tanto, más variedad configuracional. Cuanto más especificada está, menor es su potencialidad significativa y su consiguiente materialización configuracional ${ }^{36}$.

En suma, mi análisis da por sentado que la información aspectual (hipotéticamente contenida en la EE de los predicados) y la información aportada por los argumentos del predicado (hipotéticamente codificada en la EQ) experimentan un proceso de cocomposición favorecido por el hecho de que los verbos en el léxico cuentan con una definición infraespecificada. Según esto, sólo cuando un verbo se contextualiza (cuando se cocompone con sus argumentos) se puede clasificar dentro de una u otra categoría aspectual.

En estos términos, cuando se afirma que un verbo tiene un determinado significado aspectual - por ej. escribir (poesias), evento no delimitado (actividad en el sentido de Vendler, proceso en el de Pustejovksy) - se está aludiendo sólo a uno de sus significados potenciales -dado que escribir una novela, en cambio, es dclimitado-. La hipótesis de que el verbo tenga lo que Pustejovsky llama una definición infraespecificada en la que potencialmente caben otras informaciones que sólo en determinadas condiciones contextuales se realizan explícitamente, dando lugar a las otras interpretaciones, permite salvar la paradoja, al menos terminológica, de llamar aspecto léxico a una noción que habitualmente se configura en la sintaxis. Desde la nueva pcrspcctiva, todo el aspecto léxico-sintáctico está ya potencialmente contenido en la definición de la palabra en el léxico y los elementos que aparentemente contribuyen a alterar un primitivo valor aspectual en realidad se limitan a explicitar los valores infraespecificados, ya previstos.

36 Ln esta línea apunta la tendencia señalada por Bosque (1997) en su interesante artículo sobre las colocaciones; el autor observa que los verbos transitivos que denotan acciones muy especificas, restringidas a conjuntos de entidades relativamente reducidos, no prescinden de los complementos que los designan, y considera que ese hocho apoya el análisis de las colocaciones como casos particulares de selección léxica. Como se defendía en el texto, pues, la relación entre grado de especificación léxica y optatividad de los complementos parece evidente. 


\subsubsection{El análisis de llegar y ver en términos de la EE y la $E Q$}

\subsubsection{Cuando llegar deja de expresar movimiento}

Retomemos ahora los ejemplos de (1a-b), repetidos aqui como (15):

(15) a. El atteta llegó hasta la playa la semana pasada

b. La carretera llegó hasia la playa la semana pasada

Como se recordará, los ejemplos de (15) plantean un problema tanto a un análisis lexicista como a uno sintactista, dado que presentan configuraciones sintácticas idénticas y, en cambio, denotan eventos aspectualmente distintos; lo ilustran claramente los datos de (2), donde el predicado de (15a), llegar el atleta hasta la playa se manifiesta como compatible con un adverbio deíctico - a las seis, en (2a) - y no con uno durativo - aún, en (2b) mientras que el predicado de (15b) llegar la carretera hasta la playa de (1b) se encuentra en distribución complementaria respecto de la modificación adverbial —véase el contraste entre (2c) y (2d)-. Así pues, en (15) no resulta posible, al menos de forma inmediata, atribuir al significado aspectual la selección de los argumentos y la manera en que se proyectan (lo que buscaría un análisis lexicista) ni derivar de la configuración sintáctica en que se realiza el verbo una $u$ otra interpretación aspectual (en línea con un análisis construccionista).

Mi análisis propone (en línea con la hipótesis reseñada supra, en \$2.3.1) que el verbo llegar de $(15 \mathrm{a}, \mathrm{b})$ cuenta con una definición básica en el léxico según la cual es un verbo de movimiento (más en concreto, de cambio de locación). La EE que le corresponde es la recogida en $(14 \mathrm{~d})$ del Esquema 2: es decir, la que presentan los eventos que en un punto identifican el paso de un no estado al estado opuesto (['no estar aquí' > 'estar aquí']). De acuerdo con esa definición infraespecificada, llegar requiere un argumento que describa ese cambio de estado (de locación) en un punto, por tanto, un argumento dotado de dinamismo, información recogida hipotéticamente en el quale constitutivo del nombre (cn la medida en que es información que hace referencia a su constitución interna); es el caso de el atleta en (15a). La adecuada cocomposición de la información contenida en la EE de llegar y en la EQ de el atleta desencadena la interpretación del evento predicado en (15a) como un evento dinámico, acabado y puntual, lo que determina su comportamiento sintáctico frente a la modificación adverbial ilustrado en $(2 \mathrm{a}-\mathrm{b})$.

En el caso de (1b), en cambio, el sujeto la carretera se refiere a un tipo de participante que no puede desplazarse, dado que carece de dinamismo. En principio, la cocomposición entre llegar y cualquier sujeto del tipo de la carretera debería estar excluida, pero no sólo no lo está sino que es muy frecuente, y en muchas lenguas. El mecanismo que permite la interpretación del cjemplo de (15b) es el de coacción y opera, de acuerdo con mi hipótesis, del siguiente modo: la carretera es un argumento que denota extensión. El verbo llegar cuenta en su EE con una fase de estado a lo largo de la cual se puede extender un argumento. Los argumentos no dinámicos, incapacitados para describir cl paso de un estado a otro, coaccionan al verbo para denotar solo la fase a lo largo de la cual se extienden. Cuando eso ocurre, la primera fase (la del no estado) queda oculta y se pierde, por tanto, el significado de cambio: el verbo deja de expresar movimiento y pasa a interpretarse como estático, por tanto durativo. Si solo se focaliza la fase del estado cn la que se encuentra el argumento, la 
interpretación se aproxima a la del verbo haber. En efecto, cuando la EE de (14d) pierde la fase inicial se asimila a la de los estados recogida en (14a) y de ello deriva el comportamiento sintáctico que manifiesta llegar en (2c-d).

Para que la interpretación estativa de llegar sea posiblc, cs obligada la presencia de hasta la playa, constituyente prescindible en (15a), dado que un evento de cambio de locación no exige una mención del límite espacial del movimiento descrito. En cambio, en (15b) sí es necesario, dado que la expresión del evento en el cual un argumento se extiende a lo largo de una fase sí requiere una mención de desde dónde o hasta dónde «llega» su extensión. Con esto estoy proponiendo que hasta la playa contribuye de manera fundamental a que se descncadene una de los significados potenciales de llegar contenido en su definición infraespecificada. Por otra parte, nótese que la diferente interpretación semántica, y la consiguiente diferencia aspectual, entre los predicados de (15a) y (15b) no puede atribuirse a la naluraleza animada o inanimada del argumento sujeto (el atleta/la carretera). Como ya se adelantó, obtenemos los mismos efectos en una oración ambigua como el niño llega hasta el botón del ascensor, quc manifiesta un comportamiento sintáctico dispar, en sintonía con cada una de sus lecturas - como evento dinámico se combina con un adverbial deíctico (en este momento), como estático, con un adjunto delimitador (desde el suelo, desde ayer...)-., con un sujeto animado el niño en las dos interpretaciones. La explicación reside en que el niño se puede concebir como una entidad dotada de dinamismo o se puede entender como una entidad con extensión (la altura del niño), información de tipo subléxico relativa a la naturaleza del referente que ha de estar contenida en la EQ de niño y puede, a través de la coacción y la cocomposición, intervenir en la materialización de la EE de llegar ${ }^{37}$.

De acuerdo con el análisis defendido, llegar ha experimentado en (15b) una cxtensión semántica por la cual se modifica su interpretación (como verbo de movimiento) y su primitiva especificación aspectual (como evento dinámico, acabado y puntual), con independencia de su proyección o configuración sintáctica. El hecho de que los verbos de movimiento experimenten a menudo extensiones metafóricas o metonímicas se puede atribuir, desde una perspectiva cognitiva, a la tendencia natural de los hablantes a reinterpretar como espaciales nociones pertenecientes a otros ámbitos (cfr. Cifuentes, 1999, quien proporciona una interesante explicación del movimiento ficlivo desde esta perspectiva) ${ }^{38}$. Pero cn mi hipótesis es fundamental el hecho de que llegar (como los demás verbos) tiene en el léxico una definición poco especificada, que le permite entrar potencialmentc cn distintas configuraciones: como ya dije, cuanto más especificado léxicamente esté un verbo, más fija será su

37 Por supuesto, no toda extensión de significado es posible: llegar no tiene una fase de proccso en su estructura eventiva, según se ve en (14d) y, por tanto, cs dificil que en una extensión metafórica acabe denotando ese tipo de evento. En cambio, salir (al que hemos atribuido una estructura de tipo T2, la recogida en (141)), sí contiene una fase de proceso, lo que permite que, con un sujelo el agua, admita la combinación con aún, excluida con Juan: el agu cuin sule del piso/ Juan(*aún) sale del piso (a menos que se interprete el evento en un sentido habitual, lectura que se vería favorecida por la prescncia de algún adjunto del tipo con el cigarro en la boca). Cfr. Para más detalles sobre esta cuestión De Miguel y Fernández Lagunilla (en prensa).

38 Véase también Galán (2003) respecto de la explotación metafórica de las nociones espaciales. Radulescu (2004) analiza las expresiones idiomáticas del campo de la conversación que hacen uso de la metáfora del movimiento (no sé por dónde vas, a dónde quieres llegar, me he perdido, te has ido por los cerros de Ubeda, no te andes por las ramas, das muchos rodeas, etc.), cesde una perspectiva cognitiva pero haciendo uso también de algumos supuestos de la 'leoría del Lexicón Generativo. Véase asimismo, Serradilla (en prensa) sobre las expresioncs idiomáticas con verbos de movimiento en español. 
configuración sintáctica y cuanto menos especificado, más polisémico y más posibilidades de variación tendrá ${ }^{39}$.

En suma, la explicación propuesta para el contraste entre (15a) y (15b) implica suponer, como he hecho, que llegar tiene una definición infraespecificada que sc matcrializa en uno $u$ otro de sus sentidos potenciales en combinación con otros elementos que intervienen en la predicación, desencadenando que lo que sale a la sintaxis tenga uno u otro comportamiento sintáctico y una u otra interpretación. El análisis toma en cuenta no sólo la estructura interna del evento denotado por el verbo (esto es, la estructura eventiva o subeventiva) sino también la información contenida en la Estructura de Qualia de las palabras. Y de él deriva la importante consecuencia de que lo que se ha llamado normalmente la naturaleza composicional del aspecto léxico puede verse como una propicdad que se manifiesta en la sintaxis pero que se constituye en realidad en el léxico.

\subsubsection{La polisemia de ver}

Retomo ahora los ejemplos de (1c-d). Como vimos en (3a-b) supra, manifiestan un comportamiento dispar frente a la pasiva que, en principio, no parece derivar de las restricciones aspectuales clásicas de esta construcción. La explicación que aquí proporciono parte de la hipótesis (defendida en De Miguel, en prensa) de que, en realidad, las distintas restricciones aspectuales que presenta la formación de pasivas en español no son sino la manifestación sintáctica de un proceso de co-composición léxica que determina la clasificación eventiva de los predicados y su comportamiento frente a los fenómenos sintácticos. En (16) se rcpiten con otra numeración los ejemplos de (3a-b), junto con otros datos relativos al clítico culminativo:

(16) a.?? El castillo fue visto por Juan desde el coche.

b. El castillo fue visto por muchos turistas hasta las cinco de la torde.

c. Juan (* ${ }^{*}$ e) vio el castillo desde el coche

d. Los turistas se vieron el castillo en un par de horas

Al igual que ocurria con las oraciones de (15), los datos de (16) plantean una cucstión difícil de explicar para los análisis habituales. Lá de por qué un mismo predicado (un mismo verbo y un mismo argumento objeto) muestran un comportamiento dispar frente a fenómenos como el de la pasiva o la coaparición con el clítico culminativo. Puesto que en ambos casos, el predicado es aspectualmente idéntico en apariencia, se hace necesaria una explicación que vaya más allá de la estructura subeventiva del verbo. A propósito de ver, en De Miguel (1999) ya se recogía la diferencia aspectual que implicaba el hecho de que el evento de percepción tuviera lugar sobre uno u otro tipo de objeto: en efecto, no parece difícil argumentar, en términos de duración y agentividad o voluntariedad del evento, que ver una exposición es un evento distinto a ver la cima. Los eventos descritos por los predicados ver \{la cima, la costa\} son logros que culminan en un punto (el punto en que tiene

39 Castillo (2002) atribuye también el hecho de que verbos como llegar, ir y venir tengan un comportamiento sintáctico especial a su escasa carga semántica, que cquipara a la de los verbos copulativos. Fn opinión de la autora ello les capacita para extender más fácilmente su significado. 
lugar la percepción visual) y carecen de un estado resultante subsiguiente, aunque pucden ir seguidos de un proceso ${ }^{40}$ : lcs corresponde, en los términos de mi hipótesis, la EE de un Iogro complejo tipo <L3 [L,P] $>$, (14f) en el Esquema 2. En cambio, los eventos denotados por ver \{una exposición, la pelicula\} son eventos con duración y un estado final: en términos de nuestra clasificación de eventos, les corresponde la $\mathrm{EE}$ de las transiciones tipo $<\mathrm{T} 1$ [P, L $[\mathrm{L}, \mathrm{E}]]>,(14 \mathrm{c})$ en el Esquema 2.

Si se acepta la hipótesis defendida en De Miguel (2000), según la cual la pasiva es una operación aspectualmente orientada, que consiste en la focalización de la fase [L,E] de la EE del verbo con que se forma, se explica por qué los predicados del tipo ver la exposición aceptan formar pasiva (la exposición de Vermeer fue vista por miles de madrileños) y por qué los del tipo de ver la cima no (la cima fue vista por los excursionistas), dado que estos últimos no cucntan con una fase de L+E en su EE y los otros sí.

Con todo, esta explicación no resuelve dos problemas que plantean los datos (revisados con más detalle en De Miguel, en prensa). El primero es de indole teórica y tiene que ver con por qué el tipo de objeto (la cima, la exposición) con que se construye el verbo ver determina su interpretación aspectual. Formulado en otros términos, por qué se denomina aspecto léxico de un predicado a una noción que parece construirse en la sintaxis, una vez que se decide cuál es el objeto. El segundo problema es de naturaleza más propiamente empirica y tiene que ver con cómo se explican los datos de (16), donde el objeto que se ve es el mismo (el castillo) y, en cambio, la interpretación aspectual no (ni el consiguiente comportamiento sintáctico). Uno y otro asunto han sido ya tratados (en De Miguel, en prensa, y De Miguel y Fcrnández Lagunilla, en prensa). Pero es el momento de retomatlos en relación con el análisis proporcionado en $\$ 2.3 .2 .1$ para llegar.

Como se recordará, mi hipótesis presupone la existencia de entradas infraespecificadas en el léxico. En el caso de ver propongo que le corresponde una $\mathrm{EE}$ que contiene, al menos, un logro (el punto en que se produce la percepción visual). Si la naturaleza del objeto visto (una cima o la cosa) permite que una vez producido el primer momento de la percepción visual ésta se siga dando durante un tiempo, cl evento de logro irá seguido de una fase de proceso: la EE obtenida es un logro de tipo $<\mathrm{L} 3$ [L,P] $>$, (14f) en el Esquema 2, que excluye la pasiva y también el clítico culminativo. Este es el caso del predicado de (1c), ver el castillo desde el coche, donde el objeto percibido puede seguirse viendo una vez producida en la retina la primera impresión. Dada la EE propuesta para este predicado, se entiende que no acepte pasiva ni clítico culminativo, procesos que coinciden en seleccionar verbos con una fase de [L,E] en su estructura interna. Así se explica la inaceptabilidad de (I6a) y la de (16c) con el clítico se.

40 Como ya señaló Bello (1847). Véase a este respecto De Miguel (1999). Tambićn Horno (en prensa), quien sigue a De Miguel (1999) en la consideración de ver como evento complejo - compuesto de dos fases internas: un logro ingresivo que da cuenta de la experiencia de percibir instantáneamente con el sentido de la vista y una segunda fase, en la que la experiencia puede seguirse dando- proporciona una explicación de la poliscmia del verbo ver en línea con Pustejovsky. Para la autora, cn efceto, ver puede denotar un evento de experiencia (percepción pura, no agentiva) o una actividad volitiva por parte de un agente. En su interesante trabajo, Horno propone que la percepción visual es básica en el sentido de que los verbos que la lexicalizan son los que más tienden a la polisemia (frente a otros tipos de percepción, que con frecuencia remiten metafóricamente a ella). Horno hace derivar de la escasa especificación de ver su polisemia y su capacidad para entrar en múltiples contextos sintácticos (frente a mirar y otros verbos de percepción visual, con un contenido semántico más especificado y por tanto más reducidos contextos sintácticos) y, por supuesto, su capacidad para aparecer en expresiones idiomáticas (quc no son sino extensiones metafóricas de su significado). 
Ahora bien, si el objeto que desencadena la pcrcepción visual ticne en su EQ información sobre su estructura interna, cabe la posibilidad de que sea percibido no como una entidad atómica, en su configuración externa, sino en su dimensión interna. Es lo que ocurre típicamente con la exposición (nombre eventivo, cuya única posibilidad de ser visto es la de ser recorrido en su extensión) y es lo que puede ocurrir con la pelicula, si se concibe como un nombre de creación artística, con un desarrollo interno y una secuencia, en lugar de como un objeto (el rollo, la cinta de vídeo, el DVD, el soporte físico en que esté grabada). En estos casos, el evento de ver tiene una duración previa al final (no es puntual) y alcanza un final: una vez que se acaba la visión de estos objetos, el evento no se sigue dando; en todo caso, se puede volver a dar. Por tanto, $\mathrm{cl} \mathrm{L}$ que representa de forma infraespecificada el punto en que se produce la percepción visual se construye con una fase previa a la izquierda de $\mathrm{P}$ y otra de $\mathrm{E}$ a la derecha. Con ello se obtiene la $\mathrm{EE}$ de una transición $\langle\mathrm{T} 1[\mathrm{P}, \mathrm{L}[\mathrm{L}, \mathrm{E}]\rangle$ en $(14 \mathrm{c})$ ).

Si volvemos ahora al ejemplo de (3b), comprobamos que el castillo admite ser visto por dentro, se puede recorrer su estructura interna. Esa información ha de estar contenida en su EQ y cuando se combina con el evento de ver exige de este que tenga algo más que una fase $\mathrm{L}$ (un punto); esto es, lo coacciona, de forma que la estructura resultante $\langle\mathrm{T}[\mathrm{P}, \mathrm{L}[\mathrm{L}$, E $]]\rangle$ contiene la fase $[\mathrm{L}, \mathrm{E}]$ requerida tanto por la pasiva como por el clítico culminativo, lo que explica la aceptabilidad de (16b) y (16d) ${ }^{41}$.

El análisis aquí defondido nos exime de proponer varias entradas para verbos ver homónimos (solución que complicaría la explicación de cómo está organizado el léxico y cómo se adquiere), y coincide con lo propuesto para otro tipo de extensiones de significado, absolutamente regulares y productivas en las lenguas. En efecto, no estamos ante un fenómeno idiosincrásico o escasamente productivo. Antes bien, se trata de un comportamiento bastante regular en los verbos, que con frecuencia ven alterada en el contexto lo que constituiría su primitiva especificación aspectual, lo que parecería implicar que la sintaxis puede modificar las distinciones léxicas. De hecho, algunos de los datos aquí revisados parecen indicar que, en efecto, el objeto influye en la especificación aspectual de un predicado, hasta el punto de que no parece que se pueda atribuir una EE a un predicado hasta que el verbo no se cocompone con él.

Aquí se ha propuesto que si la información codificada en el quale constitutivo del nombre objeto no hace alusión a la estructura interna, el verbo ver se materializa como un evento que culmina en un punto (en el que se produce la percepción visual), punto que puede ir seguido de un proceso; y que si el referente del objeto contiene en su EQ información sobre su estructura interna, el verbo ver se materializa como un evento de transición. Este análisis da por sentado la hipótesis de que el nombre de un objeto o entidad incluye distintas informaciones subléxicas (internas a la palabra que lo refiere) codificadas en los distintos roles de la EQ. Para el caso del nombre castillo sugicro que cn cl quale formal se codifique la información específica respecto a su forma, dimensiones, orientación. Y en el quale constitutivo la información sobre su configuración interna. Puesto que no todos los

41 Agradezco a Toshihiro Takagaki los datos que me proporciona sobre pasivas perifrásticas con ver en español, procedentes del corpus de Miyamoto (en elaboración). Todos ellos corresponden a casos de ver con el tipo de objeto que implica una secuencia o una dimensión interna: los sujetos de las pasivas recogidas por el lingüista japonés son siempre del tipo pelicula o programa, o sujetos que denotan individuos (del tipo Juan fue visto saliendo fde tu casáen la fiesta\}). Como el propio Takagaki me señala, en este caso no se ve al individuo cono una entidad con una configuración externa, sino que lo que se percibe es un evento, en el que el individuo se desenvuelve. 
objetos que se pueden percibir se pueden recorrer internamente con la mirada (por ejemplo, un árbol o la cima sólo pueden ser recorridos externamente con la vista), la información de los argumentos en la EQ resulta crucial para cl tipo de EE en que participan.

Con esta propuesta de análisis he intentado dar respuesta al segundo de los problemas planteados más arriba: el de por qué la percepción de un mismo objeto (por ejemplo, el castillo) se puede expresar lingüísticamente de dos mancras y tiene consecuencias en la interpretación aspcctual. Queda por responder la segunda de las cuestiones planteadas: si el objeto interviene en la determinación aspcctual del predicado, ¿quiere esto decir que el aspecto léxico es, en realidad, una noción sintáctica y que, por tanto, no se pueden clasificar los verbos por su aspecto léxico? Pues bien, la hipótesis que subyace a mi propuesta de análisis considera que la respuesta es en ambos casos negativa. Si cl objeto interviene en la especificación aspectual del verbo es porque la posibilidad que materializa estaba prevista en el léxico. De hecho, no cualquier «alteración» aspectual es posible. El supuesto de que los verbos cuentan con definiciones infraespecificadas (potencialmente capacitadas para materializarse de una u otra forma) junto con el supuesto de que las estructuras internas de los eventos en el léxico están máximamente articuladas (a la mancra de las piezas de un mecano), de forma que se les pueden restar y añadir fases (normalmente con los resultados recogidos en (14)), permite explicar la polisemia del verbo ver, como explicaba las extensiones metafóricas de llegar. Las operaciones de coacción y cocomposición que ocurren en el nivel léxico (permitidas por las posibilidades previstas en las entradas léxicas infraespecificadas) ofrecen un resultado que se proyecta en la sintaxis, con las consecuencias esperadas: que el predicado aceptc o no pasiva, clítico culminativo, etc.

Lo que me importa subrayar de esta propuesta es que no suscribe lo que tradicionalmente se ha considerado la naturaleza composicional del aspecto léxico, aunque es cierto que podria parecerlo. En efecto, aquí se propone que las propiedades aspectuales de los eventos denotados por los predicados verbales interactúan con cierto tipo de informaciones contenidas en los argumentos seleccionados por los verbos, que contribuyen a definir aspectualmente estos y que en ocasiones alteran su primitiva clasificación aspectual. Con ello parece sugerirse que el aspecto se compone en la sintaxis pero no es así. El supuesto básico de este trabajo es el de que si existen altcraciones aspectuales de los verbos es porque estos presentan en el léxico entradas infraespecificadas cuyas informaciones potenciales se materializan en uno u otro sentido cuando se contextualizan en adecuada cocomposición con la EQ de los argumentos. En suma, parece oportuno abandonar la idea de la snaturaleza composicional del aspecto léxico» y usar la definición más apropiada de la «naturaleza léxica del aspecto composicional $»^{42}$.

\subsubsection{De nuevo sobre empezar}

Ya para acabar rccupero los ejemplos de (le-f) que, como veíamos en (3c-d), mostraban también un comportamiento dispar frente a la pasiva. Los incluyo de nuevo en (17) con otros datos obre el clítico culminativo:

42 Que es precisamente el título de De Miguel y Fernánder Lagunilla (en prensa). 
(17) a. La tarta fue empezada por el cocinero sin ayuda del pinche

b.??/\# La tarta fue empezada por el niño sin permiso

c. */\# El cocinero se empezó la tarta sin ayuda del pinche.

d. El niño se empezó la tarta sin permiso

En (17) se ilustra un caso más de predicados configuracionalmente idénticos, formados sobre el mismo verbo (empezar), pero con diferencias interpretativas y consecuencias sintácticas dependiendo de cuál sea, en cada caso, el sujeto lógico (el cocinero o el niño). De manera muy resumida, y siguiendo el análisis defendido en los epígrafes precedentes, propongo que empezar está incluido en el léxico con una definición infraespecificada, que le permite combinarse con eventos, y con objetos que puedan ser coaccionados para interpretarse como eventos. Como se ilustró más arriba en (6), cuando se combina con la novela puede entenderse que empezar la novela equivale a empezar a escribirla o a empezar a leerla, porque el nombre novela contiene en su EQ información sobre ambos eventos. Sólo cn la segunda interpretación acepta el clítico culminativo (cfr. (9)), porque este requiere un objeto preexistente, información que no está implicada necesariamente por el quale agentivo. En la interpretación correspondiente al quale agentivo el evento denotado por empezar constituye una transición que termina con un evento de logro tipo $<\mathrm{L} 2[\mathrm{~L}, \mathrm{E}]>((14 \mathrm{c})$ en el Esquema 2): culmina en un punto y da lugar a un estado nuevo (la existencia parcial de la novela: la total se alcanza cuando 'se acaba'); puesto que en ese caso la EE cuenta con una fase $[\mathrm{L}, \mathrm{F}]$, el predicado admite pasiva, como se ve en (18a). En cambio, en la interpretación correspondiente al quale télico, el objeto novela preexiste, y no cambia de estado porque el sujeto comience a leerla. Hasta que la lectura no acaba, no existc un estado que siga al punto culminante. Si el logro que sigue al proceso no va seguido a su vez de un estado nuevo, la transición tiene la EE <T1[P,L]> y por ello en esta lectura no se admite pasiva: se ilustra en (18b):

(18) a. La novela fue empezada por su autor antes de conocer a la que sería su musa b. * La novela fue empezada por la página 8

Pues bien, la misma explicación se puede proporcionar para el contraste de (17a-b). Cuando el cocinero cmpieza una tarta, se supone que inicia el proceso de su elaboración; por lo tanto, la tarta pasa parcialmente a existir, y la pasiva se acepta (17a). En cambio, cuando el niño empieza la tarta, se interpreta que empicza a comérsela. Desde el punto de vista lingüístico, no se expresa un cambio de estado; este se produce cuando la tarta se acaba y por ello la oración (17b) es agramatical. Sólo si se interpreta quc cl niño ejerce de cocinero, caso en que el quale scleccionado sería el agentivo, la oración sería aceptable, posibilidad que recoge el signo que precede al ejemplo.

En cambio, respecto del clítico culminativo los juicios sobre la aceptabilidad de los predicados son los opuestos, a pesar de que los requisitos que hemos atribuido al clítico y la pasiva coinciden: la existencia de una fase [L,E] en la EE del verbo. Ahora bien, la explicación del difcrente comportamiento trasciende el análisis en términos de fases. Como ya se dijo a propósito de (9), el clítico culminativo requiere la preexistencia del objeto (porque solo de un objeto que existc se puede predicar un cambio de estado) y el quale agentivo no la presupone. De ahi la inaceptabilidad de (17c), dado que la tarta no preexiste cuando $\mathrm{cl}$ cocinero inicia su elaboración, por lo que no es compatible con un clítico que señala que en 
una fase el evento ha culminado y ha dado paso a un estado nuevo en el argumento objeto (a menos, por supuesto, que se interprete que el cocinero 'empezó a comerse, no a haccr, la tarta'). En cambio, en (17d) si se acepta el clítico culminativo cuando se interpreta que $e l$ niño empieza a comerse una tarta preexistente.

\subsection{Recapitulación: que significan aspectualmente los verbos y qué pueden llegar a significar}

La propuesta de este trabajo se asienta sobre el supuesto de que los verbos cuentan en el léxico con definiciones infraespecificadas cuyas potencialidades se pueden materializar en uno u otro sentido (aspectual, configuracional, o ambos) en virtud de la información aportada por los argumentos (sujcto y/o complementos, y aun adjuntos) con que se cocompongan. En los roles de la FQ de los nombres se codifica información que se cocompone (en ocasioncs, prcvia modificación o coacción de los contenidos) con la contenida en la EQ y en la $\mathrm{FE}$, de los verbos. La información relativa al tipo de evento denotado por el verbo aislado de contexto está probablemente contenida en el quale formal, aquel que codifica información por la cual los objetos se distinguen de los de su misma clase: el tipo de evento especificado se manifiesta después en la estructura de fases a EE particular. E1 resto de informaciones que se manifiestan en lo que tradicionalmente se han denominado las restricciones de selección están repartidas en los otros qualia, y se co-componen con la información recogida en la EQ de los argumentos del prodicado: así, el quale constitutivo, el télico y el agentivo contendrán informaciones relativas a cómo es la constitución interna del evento, cuál es su objetivo básico y cómo ha llegado a existir, informaciones que se combinarán adecuadamente con las del mismo estatus contenidas en la EQ de los argumentos del predicado. Desde esta perspectiva, las diferencias entre ser verbo de acción o de movimiento, de manera de movimiento o de desplazamiento, estarán probablemente contenidas en el quale constitutivo. Unas y otras informaciones subléxicas determinan ciertos comportamientos sintácticos que diferencian entre verbos que pertenccerían, en principio, a una misma clase aspectual. Ello explica, por ejemplo, que verbos aspectualmente idénticos se comporten de diferente modo frente a procesos que se dan en la sintaxis y que parecen condicionados por el aspecto; acabamos de verlo, en la sección anterior: la pasiva perifrástica y el clítico culminativo ticne un mismo requisito sobre la $\mathrm{EE}$ de los verbos transitivos, de forma que los verbos que aceptan una deberían aceptar el otro, pero no siempre es así; tampoco la coaparición de los verbos de una misma clase aspectual con predicativos intercambiables por modificadores adverbiales de manera se explica sólo en términos de EE (cfr. De Miguel y Fernández Lagunilla, 2004); otro tanto ocurre con la formación de pasivas con se, ser y estar (cfr. De Miguel, en prensa). También se explica así la cucstión fundamental de por qué el evento denotado por un verbo (por ejemplo, el logro de llegar) se puede reinterpretar como un estado, y por qué un mismo verbo expresa a veces un estado, a veces un proceso y a veces una transición: como ocurre con Juan escribe y sus posibles interpretaciones (=‘es escritor'; 'a menudo'; 'cstá cscribiendo algo en este momento').

De la propuesta aquí defendida se sigue que existen muchas posibilidades nuevas para clasificar los verbos, y que unos parámetros se cruzan con otros. Así, dentro de los verbos de logro puntuales (los que tiene la EE de (14d)), unos serán de movimiento y otros no, de acuerdo con la información contenida en el quale agentivo; eso no excluye que no acep- 
ten similares extensiones metafóricas: la carretera sale de la montaña y llega al valle; la carretera nace en la moniaña y muere en el valle, en la medida en que estas se producen por medio de procesos que operan sobre la EE, que es compartida. Pero habrá diferencias sustanciales motivadas por las informaciones subléxicas contenidas en los otros roles ${ }^{43}$.

Así pues, las posibilidades de clasificar los verbos han aumentado. La idea de que, en principio, hay verbos, como ver, que no se pueden adscribir a una única clase -o que al menos, no se pueden adscribir a una clase hasta que no se sepa si se construyen o no con complemento y cuál cs $\operatorname{cstc}^{44}$; o que con un mismo complemento (el castillo) se pueden adscribir a dos clases distintas - es en realidad un malentendido, si se considera, como defiendo aquí, que el aspecto cn cfecto tiene una naturaleza composicional, pero se compone en el léxico no en la sintaxis. Es en ese nivel donde tienen lugar las operaciones que desembocan en que a la sintaxis llegue un tipo determinado de cvento con un comportamiento sintáctico previsto de antemano. En definitiva, se pueden establecer clases de EE y se pueden clasificar los verbos, aislados de contexto, como pertenecientes a una u otra de estas clases. Se pueden proponer otras clasificaciones subléxicas, basadas en la información contenida en la EQ. Y finalmente, se debe tener en cuenta que ciertos mecanismos que operan en el léxico pueden desencadenar una potencialidad de la entrada léxica de un verbo con el resultado de que este puede inscribirse dentro de otra clase (lo que ocurre cuando pierde o gana una fase).

\subsection{Predicciones del análisis}

El análisis propuesto tiene multitud de conexiones y posibles aplicaciones, y el modelo de Pustejovsky en el que se basa resulta sumamentc atractivo para el lingüista interesado por la relación entre el léxico y la sintaxis. Un conjunto de fenómenos tradicionalmente considerados esquivos para las hipótesis habituales, parece alcanzar un principio de explicación desde esta perspectiva de análisis que integra diversos tipos de información contenidas en la entrada léxica de las palabras ${ }^{45}$.

Mencionaré sólo un par de cuestiones que me parece que se pueden investigar teniendo en cuenta los supuestos de la hipótesis aquí defendida: en primer lugar, el estudio de las expresiones idiomáticas se ha de ver beneficiado de la aplicación de un análisis en términos de la interacción entre EE y EQ. Las extensiones de significado, en efecto, pueden recibir una explicación no ad hoc ni de tipo enciclopédico, sino relacionada con mecanismos que

43 Abad (2004) lleva a cabo un exhaustivo estudio del comportamiento sintáctico de los adjetivos relacionales en función de qué información de la EQ del nombre materializan (la correspondiente al quale têlico, al agentivo, al formal o al constitutivo), con resultados muy relevantes que confirman el interés de esta línea de investigación.

44 Hecho que estaba en la base de la objeción tantas veces formulada a la clasificación de Vendler (1967). En efecto, ha sido frecuente en la bibliografia sobre aspecto la crítica de que Vendler ejemplificaba la diferencia entre realizaciones y actividades por medio de predicados y no de verbos (constrair una casa/consinuir (casas)). Sin embargo, no se debe olvidar que Vendler era filósofo y que propuso una clasificación de los tipos de situación, no de los tipos de verbo, y que son los lingüistas quienes han explotado con posterioridad su propuesta (cfr. De Miguel, 1999 a este respecto)

45 Por otra parte, el modelo de explicación basado solo en la EQ resulta igualmente prometedor. En concreto, algunos problemas clásicos de la gramática, como por qué ciertos adjetivos se adverbializan (del tipo de claro en hablar claro) o se sustantivan (móvil en me he comprado un móvil) y otros en cambio no, parecen explicarse en términos de la información hipotéticamente codificada en los roles de la Estructura de Qualia. (Cf: Abad, 2004 y De Miguel y Fernández Lagunilla, 2004). 
operan con la información contenida en ambas estructuras. Piénsese, por ejemplo, en cl significado coloquial del verbo machacar como insistir; sin duda, la idea de repetición contenida en la definición infraespecificada del verbo (una sucesión de eventos de L1) permite que, combinado con un complemento del tipo tema (cuyo quale agentivo codifica información relativa a que es 'algo (de 10) que se habla'), adquicra el valor metafórico de 'repetir, insistir hasta la saciedad', extensión de hablar una y otra vez $(L, L, L)$ de lo mismo (del tema) ${ }^{46}$. En consecuencia, un campo de estudio algo relegado en los análisis formales se convierte en objeto de un renacido interés enfocado desde esta perspectiva.

El segundo fenómeno cuyo estudio queda pendiente de una investigación futura pero del que quiero dejar aquí constancia por las perspectivas que abre la hipótesis de $\$ 2$ para su explicación es el de la discutida condición de las pasivas con estar. Como señala Marín (2004: 28-29), ciertos verbos claramente perfectivos las rechazan, a menos que aparezca explícito el sintagma-por (este cuadro está pintado "(por Velázquez); este edificio está construido *(por Fisac)), restricción que se ha atribuido normalmentc a razones de tipo informativo. Ahora bien, encontramos una situación parecida con otros verbos, que parecen monos perfectivos (las alergias están provocadas *(por muchas causas)), lo que recomienda en principio desvincular la explicación del aspecto. Pero aún hay más: hay verbos perfectivos que no aceptan la pasiva con estar, ni siquiera con la presencia explícita del sintagma-por: *la sonata está interpretada *(por la orquesta); *el gol está marcado *(por Torres); ahora bien, estos últimos vcrbos sí aceptan la pasiva con ser, siempre y cuando se materialice el sintagma-por o algún otro adjunto que complete la predicación: la sonata fue interpretada *(\{por la orquesta, magistralmente\}); el gol fue marcado *(\{por Torres, en el minuto 90\}). Marín propone explicaciones relacionadas con el tipo de información aportada por el predicado (esto es, de corte pragmático), o relacionadas con la función semántica del argumento (afectado o de trayectoria), pero no acaba de resolver el problema. En mi opinión merece la pena intentar una explicación en términos de $\mathrm{EQ}$.

Nótese que los ejemplos que requieren el sintagma-por son aquellos en que el verbo es de creación y se combina con el quale agentivo del nombre para dar lugar a la existencia de un objeto. La presencia del agente en el sintagma-por parece obligada para materializar el quale agentivo del verbo. Esto es, mi propuesta sugiere que el sintagma-por es obligatorio cuando el verbo es de aquellos en los que el objeto se crea a través de la actividad del agente. Aquí se incluyen los eventos espaciales, en lo que el objeto se crea en el sentido de que se delimita, adquiere contorno, a través del referente del sintagma-por: el prado está limitado *(por la valla); el valle está cruzado "(por el rio); la ciudad está rodeada por montañas)"17.

46 La idea está inspirada en la propuesta de Bosque (2001), quien defiende que un verbo como cometer en expresiones como cometer un crimen es la forma verbal cspecífica que el léxico proporciona para llenar un contenido aspectual cercano a lograr o simplemente hacer, cuando se habla de crimenes. Para el autor, el quale télico de Pustcjovsky es una opción para formular esta relación especíicu en el léxico (que no es cxactamente la de una expresión idiomática): la de denotar que 'pasa a existir un evento o cstado' (en su ejemplo, un crimen).

47 A memudo se ha llamado complemento agente al sintagma-por aunque, desde un punto de vista semántico, no tiene por qué ser agentc ( $y$, desde un punto de vista sintáctico, es discutible si es un adjunto o un argumento). En efecto, el sintagma-por puede ser una meta (los libros fueron recibidos por el periodista) o un tema, como en los ejemplos mencionados en el lexto en los que una entidad ubicada en cicrto lugar delimita ese lugar (el prado esía limitado por la valla). Ahora bien, si se considera que el sintagma-por, con independencia de su función semántica - papel temático, es la materialización o saturación del quale agentivo, el término tradicional se vuelve bastante más apropiado. 
También en las pasivas con ser resulta obligado el sintagma-por si el verbo es de creación, como en los casos ya mencionados de interpretar una sonata o marcar un gol: la sonata se re-crea a través de su interpretación y el gol pasa a existir cuando es marcado, a través de determinada actividad llevada a cabo por un futbolista. La razón por la que estos verbos no aceptan, en cambio, la pasiva con estar tiene que ver con que en ellos el objeto que pasa a existir tiene una existencia efímera: no se mantiene (como el cuadro una vez pintado o el edificio una vez construido) y la pasiva con estar, es una estructura que focaliza un resultado que se mantiene (cfr. De Miguel, 2000).

Estos son sólo un par de ejemplos (merecedores, obviamente, de mucho más que esta simple mención) de por dónde puede avanzar la investigación aquí esbozada y en qué medida puede contribuir a aumentar nuestro conocimiento acerca de los significados aspectuales de los verbos, acerca de las ampliaciones del significado aspectual que experimentan y acerca de las clascs aspectuales en las que los podemos distribuir, de acuerdo con sus definiciones básicas o infraespecificadas.

\section{Conclusión}

A lo largo de las páginas precedentes he intentado argumentar a favor de la posibilidad de que las informaciones codificadas en las estructuras internas de las palabras (fundamentalmente, en la Estructura Eventiva y en la de Qualia) interactúen para determinar su significado en los distintos contextos, tal y como propone Pustejovsky (1991 y siguientes). En el caso de los verbos, de ese significado especificado (de entre una gama de posibles especificaciones previstas en la entrada léxica) derivará el comportamiento frente a un buen número de procesos sintácticos (pasividad, modificación adverbial, clítico culminativo) y semánticos (las llamadas extensiones metafóricas y posiblemente las expresiones idiomáticas).

La hipótcsis de la interacción entre EE y EQ permite salvar problemas teóricos resistentes a otras explicaciones: la naturaleza aparentemente sintáctica del aspccto léxico, la paradoja de que predicados configuracionalmente idénticos se interpreten aspectualmente de forma distinta, el hecho inesperado de que un mismo verbo con un mismo objeto reciba varias interpretaciones aspectuales, ctc. La noción de infraespecificación y los mecanismos de coacción y cocomposición permiten hacer uso de un concepto más amplio de la aspectualidad a través del cual se pueden explicar csos y otros fenómenos. Esa noción ampliada de la aspectualidad considera que toda la información atribuida normalmente al aspecto léxico se construye efectivamente en el léxico, en el mismo sitio donde está el resto de las restricciones de selección léxica. Desde esta perspectiva, las clases verbales no constituyen entidades primitivas sino generalizaciones aproximativas sobre posibilidades previstas en el léxico, probablemente en la $E Q$ de las palabras en combinación con la información derivada de la estructura de fases del evento. Se trata, pues, de una información que se obtiene geométricamente, de forma estructural, para lo que precisamos un modelo de organización del léxico que permita que los verbos se interpreten como constructos geométricos que pueden crecer a través del encajc o combinación de piezas más simples, como el de Pustejovsky $(1991,1995)$ del que nos hemos servido. 


\section{REFERENCLAS BIBLIOGRÁFICAS}

Abad Pastor, R. (2004): Los adjetivos relacionales en la interficie léxico-sintáctica. Trabajo de Investigación Tutelado inédito, Universidad Autónoma de Madrid.

Alcoba, S. (1999): «La flexión verbal». En Bosque, I. y V. Demonte (dirs.), págs. 4915-4991.

Alexiadou, A., E. Anagnostopoulou y M. Everaert (eds.) (2003): The Unaccusativity Puzzle: Explorations of the Syntax-Lexicon Interface. Oxford, Oxford University Press.

Batsiukova, $\mathrm{V}$. (en prensa 1): «Operadores aspectuales en ruso: su estructura eventiva y su función en la representación formal de la oración', Revisła Española de Lingüística, 2003, 2.

Batsiukova, V. (en prensa 2): «Direccionalidad de los verbos de movimiento. Un análisis subcrentivo», Interlingüistica, 15.

Bello, A. (1847) [1981]: Gramática de la lengua castellana destinada al uso de los americanos, ed. crítica de Ramón Trujillo. Tenerife, Aula de Cultura de Tenerife.

Bcrtinctto, P. M. (1981): «Il carattere del processo («Aktionsart») in italiano. Proposte, sintatticamente motivate, per una tipologia del lessico verbales, en VVAA, Tempo verbale, strutture quantificate in Forma logica. Florencia, L'Accademia della Crusca, págs. 11-90.

Bjerre, T. (1999): «Event Structurc and Support Verb Constructions», en Todirascu, A. (ed.), Proceedings of theESSLLI Student Session, Capítulo 1, págs. 3-15.

Bosque, I. (1989): Las Categorias Gramaticales. Relaciones y Diferencias. Madrid, Sintesis.

Bosque, I. (1997): «Objetos que esconden acciones. Una reflexión sobre la sincategorematicidad», En Cabré, T. y C. Gelpi (eds.): Léxic, Corpus i Diccionaris. Cicle de conferències i seminaris '97-'98. Barcelona, Institut Universitari de Lingüística Aplicada, págs. 15-31.

Bosque, I. (2001a): «On the weight of light predicates». En Herschenson, J., K. Zagona y E. Mallén, (eds.): Features and Interfaces in Romance. Amsterdam, John Benjaminn, págs. 23-38.

Bosque, I. (2001b): «Sobre el concepto de 'colocación' y sus límites», Linguilistica Española Actual, XXIII,1. Volumen monográfico sobre Las Colocaciones.

Bosque, I. y V. Demonte (dirs.) (1999): Gramática Descripitiva de la Lengua Española. Madrid, Espasa-Calpe.

Campos, H. (1999): «Transitividad e intransitividad». En Bosque, I. y V. Demonle (dirs.), págs. 15211574

Cano Aguilar, R. (1981): Estructuras sintácticas transitivas del español actual. Madrid, Gredos.

Cano Aguilar, R. (1999): «Los complementos de régimen verbal». En Bosque, I. y V. Demonte (dirs.), págs. 1807-1854.

Castillo, M.E. (2002): Inacusatividad y aspecto léxico en los verbos de movimiento. Estudio diacrónico. Girona, Scripta, Documenta Universitaria.

Ciluentes, J. I. (1999): Sintaxis y semántica del movimiento. Aspectos de gramática cognitiva. Alicante, Institut de Cultura Juan Gil- $\Lambda$ lbert.

Chomsky, N. (1967) ) [1970]: «Remarks on Nominalization», en Jacobs, R.A. y P. S. Rosenbaum (eds.): Readings inEnglish Transformational Grammar. Waltham, Mass., Ginn \& Co., págs. 184-221.

Climent Roca, S. (2000): «Individuación e información Parte-Todo. Representación para el procesamiento computacional del lenguaje», Estudios de lingǘstica española, vol. 8 (revista informática, Comunidad Virtual de Usuarios asociada a Infoling).

Comesaña, S. (2002), «Los verbos de conocimiento en español: carcaterización sintáctica», Verba, 29 , pp. $243-260$.

Crystal, D. (19913): A Dictionary of Linguistics and Phonetics. Oxford, Blackwell.

Demonte, V. (2002): «Preliminares de una clasificación léxico-sintáctica de los predicados verbales del español». En S. Grosse ey Axcl Schönberger (eds.), Ex Oriente Lux. Festschrift für Eberhard Gärtner zu seinem 60. Geburtstag, Frankfurt am Mein, Valentia, págs. 121-144. 
Diaz, L., A. Bel, E. Rosado, A. Ruggia y K. Bekiou (2003): «The Role of Morphological Features in the Accuisition of Spanish Aspectual Differencess), Mamuscrito, Universitat Pormpeu Fabra y Universitat de Barcelona.

Erasmo de Rotterdam (1511) [1984]: Elogio de la Locura, edición de P. Rodriguez Santidrián. Madrid, Alianza.

Fernández, A., G. Vázquez y M.A. Martí (2002): «Alternancias diatéticas relacionadas con el aspecton, Verba, 29, págs. 389-402.

Fernández Lagunilla, M. y E. de Migucl (1999): «Relaciones entre el léxico y lá sintaxis: adverbios dc foco y delimitadores aspectuales», Verba, 26, págs. 97-128.

Fernández Lagunilla, M. y E. de Miguel (2000a): «Lat interfaz léxico-sintaxis: el clítico culminativo». En Miguel, E. de , M. Fernández Lagunilla y F. Cartoni (eds.): Solbre el lenguaje: Miradas plurales y singulures. Madrid, UAM/Arrecife, págs. 141-159.

Fernández Lagunilla, M. y E. de Miguel (2000b): «Adverbios de manera e información aspectual». En Muñoz, $M^{a} \mathrm{D}$,

A.I. Rodriguez-Piñero, G. Fernández y V. Benitez (eds.): Actas del IV Congreso de Lingüistica General. Cádiz, Servicio de Publicaciones de la Universidad de Cádiz/Servicio de Publicaciones de la Universidad de Alcalá, págs. 1009-1019.

Fernández Lagunilla, M. y E. de Miguel (en prensa): «Más allá de la información subeventiva: procesos que operan con los qualia de las palabras*. En Actas del V Congreso de Linguística General, Madrid, Arco/Libros.

Fodor, J. y E. Lepore (1998), «The Emptiness of the Lexicon: Reflections on James Pustejovsky's The Generative Lexicon», Linguistic Inquiry, 29,2, págs. 269-288.

García-Miguel, J. M. (2004): «Información sobrc cl Proyecto Alternancias de diátesis y esquemas sintácticosemánticos del español», en la dirección electrónica: http:/webs.uvigo.es/adesse/

Galán Rodríguez, C. (1993): kAproximación al estudio de los verbos de movimiento en alemán y en español: movimiento real y empleos figurados», Anuario de Estudios Filológicos, XVI, págs. $147-158$.

Gómez Asencio, J.J. (1981): Gramática y categorias verbales en la tradición española (1711-1847). Salamanca, Acta Salmanticensia.

González Muñoz, R. (2003), La Estructura de Qualia y el clitico culminativo en algunas construcciones del español con empezar, comenzar, iniciar, terminar y acabar. Trabajo de Investigación Tutelado inédito, UAM.

Grupo ILEA (2003): «Sobrc un proceso de creación de estructuras lingüísticas: el verbo salir», Interlingüistica 14, págs. 593-605.

Hale, K. y S.J. Keyser (1993): «On Argument Structure and the Lexical Expression of Syntactic Relationsm. En Hale, K. y S.J. Keyser (eds.) (1993): The View from Building 20. Essuys in Linguistics in Honor of Sylvain Bromberger. Cambridge, Mass., MIT Press, págs.53-109.

Halliday, M.A.K. (1985): An Introduction to Functional Grammar. Londres, Edward Arnold.

Hernández Paricio, F. (en prensa): «Proyección léxica e intransitividad dividida». En Actas del VI Congreso de Lingüistica General, Santiago de Compostela, Universidad de Santiago de Compostela.

Horno Chéliz, $\mathrm{M}^{a}$ Carmen (en prensa): «Aspecto léxico y verbos de percepción. A ropósito de ver y mirans. En Castañer, R.M., y J.M. Enguita (eds.): In Memoriam Manuel Alvar Archivo de Filología Aragonesa, LIX, Institución «Fernando el Católico», CSIC de la Excma. Diputación Provincial de Zaragoza.

I.evin, B. (1993): English Verb Classes and Alternations. A Preliminary Investigation. Chicago, The University of Chicago Press.

Marín, R. (2004): Entre ser y estar. Madrid, Arco/Libros.

Mendikoetxea, A, (1999): «Construcciones inacusativas y pasivas». En Bosque, I. y V. Demonte (dirs.), págs. 1575-1629. 
Miguel, E. de (1992): El aspecto en la sintaxis del español; perfectividad e impersonalidad. Madrid, Ediciones de la Universidad Autónoma de Madrid.

Miguel, E. de (1999): «El aspecto léxico». Fn Bosque, I. y V. Demonte (dirs.), págs. 2977-3060.

Miguel. E. de (2000): «Relazioni tra il lessico e la sintassi: classi aspecttuali di vcrbi ed il passivo in spagnolo». En Simone, R. et alii (eds.), Classi di parule e conoscenza Lessicale. Número monográfico de Studi Italiani di Linguistica Teorica e Applicata, XXIX, 2, págs. 201-215. También en Círculo de Lingüistica Aplicada a la Comunicación, 2001, en la dirección www.ucm.es/info/circulo/no8/ demiguel. htm

Mignel. E. de (2003): «Sobre la silepsis: un análisis léxico-semántico de la discordancia inducida por mitad's, Revista de Investigación Lingïística, VI, 1, págs. 143-173.

Miguel, E. de (en prensa), «La formación de pasivas en español. Análisis en términos de la Estructura de Qualia y laEstructura Eventiva», Verba Hispánica.

Miguel, E. de y M. Fernández Lagunilla (2000a): «El operador aspectual se», Revista Española de lingïistica, 30, 1, pp. 13-43.

Miguel, F. de y M. Fernéndez Lagunilla (2000b): «Predicación secundaria y modificación adverbial». En Actas del II Congreso de la Sociedad Española de Lingüística. Madrid, Gredos, págs. 226233.

Miguel E. de y M. Fernández Lagunilla (2004): «Un enfoquc subcventivo de la relación entre predicados secundarios y adverbios de manera", Revue Romane, 39,1, págs. 24-44.

Miguel, E. de y M. Fernández Lagunilla (en prensa): «Subre la naturaleza léxica del aspecto composicional». En Actas del VI Congreso de Lingüistica General, Santiago de Compostcla, Universidad de Santiago deCompostela.

Miyamoto, M. (en elaboración): KLM Corpus.

Morcno Cabrera, J.C. (1997): Introducción a la Lingüistica. Enfoque Tipologico y Universalista. Madrid, Síntesis.

Moreno Cabrera, J.C. (2003): Semántica y gramática. Sucesos, papeles semánticos y relaciones sintácticas. Madrid, Antonio Machado Libros.

Mosquera Nartallo, A. (2001), Los predicados emotivos: sobre temer, temor, atemorizar(se). Tesis Ductural inédita, Universidad de Santiago de Compostela,

Pérez Jiménez, I. y N. Moreno (en prensa): «¿Son todos los verbos inacusativos aspectualmente télicos en español? El papel de la telicidad on la interficie léxico-sintaxis». En Actas del VI Congrewo de Lingüistica General, Santiago de Compostcla, Universidad de Santiago de Compostela.

Pustejovsky, J. (1991): “l'he Syntax of Event Structure». En Levin, B. y S. Pinker (eds.), Lexical and Conceptual Structure. Oxford, Blackwell, págs. 47-81.

Pustejosvky, J. (1993): «Type Coercion and the Lexical Selection». En Pustcjovsky, J. (ed.): Semantics and the Lexicon. Dordrecht, Kluwer, págs.73-94.

Pustejosvky, I. (1995): The Generative Lexicon. Cambridge, Mass., MIT Press.

Pustejosvky, J. (2000): «Events and the Semantic Opposition». En Tenny, C. y J.Pustcjosvky (eds.): Events as Grammatical Objects. Stanford: CSLI Publications, págs. 445-482.

Pustcjovsky, J. y B. Boguraev (1993): «Lexical Knowdlege Representation and Natural Language Processing», Artificial Intelligence, 63, págs. 193-223.

Pustejovsky, J. y P. Bouillon (1996): «Aspectual Coercion and Logical Polysemy». En J. Pustejovsky y B. Boguracv (cds.) Lexical Semantics. The Problem of Polysemy. Oxford, Oxford University Press, págs. 133-162

Radulescu, Romana (2004), Estudio contrastivo de expresiones idiomáticas del campo de la Conversación en español, inglés y rumano. Trabajo de Investigación Tutelado inédito, Universidad Autónoma de Madrid.

Sanz, M. (2000): Events and Predication. Amsterdam, John Benjamins.

Sanz, M. y N. Fukushima (2003): Studies on the Acquisition of Spanish by Native Speakers of Japanese. Número monográfico de Annals of Foreign Studies, Vol. 57, Kobe, Kobe City University of Foreign Studies. 
Serradilla, A. (en prensa), « $r$ y caer como constituyentes de locuciones frascológicas que no implican movimienton, Verba Hispánica.

Tokunaga, Sh. (2001): Clases aspectuales de verbos en japonés y restricciones aspectuales de la formación pasiva. Tesis Doctoral Inćdita, Universidad Autónomas de Madrid.

Val Álvaro, J. F. (1999): «Sobre la naturaleza del conocimiento léxico», en Torres Sáncher, M.A (ed.), $V$ Jornadas de Linginistica. Cádiz, Universidad de Cádiz, págs. 129-171

Val Álvaro, J.F., F. Hernández Paricio, J.L. Mendivil Giró y M.C. Horno Chéliz (2003): «Alternancias verbales: estructuras subeventivas y sintaxis léxicar. Ponencia presentada en el VI Congreso Internacional de Lingüisticu Hispánica. Leipzig, noviembre de 2003.

Van Houl, A. (2002): «Projection Based on Event Structure», en Coopmans, P., M. Everaert y J. Grimshaw (eds.): Lexical Specification and Insertion. Amsterdam, John Benjamins, págs. 397-422.

Vázquez, G., A. Fernández y M.A. Martí (2000): Clasificación verbal. Alternancias de diátesis. Número monográfico de Quaderns de Sintagma, 3.

Vendler, Z. (1967): Linguistics in Philosophy. Ithaca, Comell Univcrsity Press. 